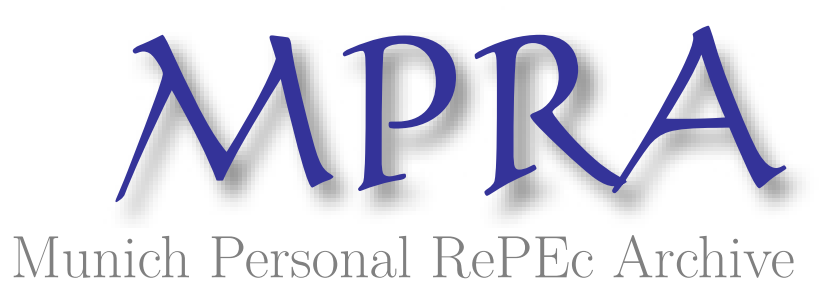

\title{
Are the Children of Uneducated Farmers Doubly Doomed? Farm, Nonfarm and Intergenerational Educational Mobility in Rural China
}

Emran, M. Shahe and Sun, Yan

1 October 2014

Online at https://mpra.ub.uni-muenchen.de/59230/

MPRA Paper No. 59230, posted 15 Oct 2014 12:01 UTC 


\title{
Are the Children of Uneducated Farmers Doubly Doomed? Farm, Nonfarm and Intergenerational Educational Mobility in Rural China
}

\author{
M. Shahe Emran ${ }^{1}$ \\ IPD, Columbia University \\ Yan Sun \\ World Bank
}

First Draft: August 6, 2014

This Version: October 1, 2014

\begin{abstract}
This paper relaxes the single factor model of intergenerational educational mobility standard in the literature, and develops a research design to study the effects of parents' education and occupation on children's schooling. We use survey data from rural China that cover three generations and are not subject to coresidency bias. The evidence from recently developed matching and propensity score weighted estimators shows that the mean effects of parents education from the standard model miss substantial heterogeneity. Within the low education subsample, a son (girl) attains about 0.80 (0.60) years of additional schooling when born into a non-farm household compared to a farm household, and among the farming households, a child gains a one year of schooling when at least one parent has more than primary schooling. Having nonfarm parents, however, does not confer any advantages over the farmer parents if the farmers are relatively more educated, even though nonfarm households have significantly higher income. This suggests that income plays a secondary role to parental education. Estimates of cross-partial effects without imposing functional form show little evidence of complementarity between parental education and non-farm occupation. The role of family background remains stable across generations for girls, but for boys, family background has become more important after the market reform.

Key Words: Educational Mobility, Inequality, Rural China, Nonfarm, Education and Occupation, Family Background, Heterogeneity, Complementarity, Market Reform, Gender Gap
\end{abstract}

JEL Codes: O12, J62

\footnotetext{
${ }^{1}$ We would like to thank Li Shi, Zhan Peng, and Song Jin for help with the CHIP survey data, and Matthew Lindquist and Forhad Shilpi for helpful comments and/or discussions.
} 


\section{(1) Introduction}

Increasing inequality despite sustained economic growth and poverty reduction in last few decades has become a central policy issue in both developed and developing countries (Stiglitz (2012), Rajan (2010), Picketty (2014)). Inequality and its negative effects have also been high on the agenda of the Chinese policymakers in recent years. ${ }^{2}$ There is a broad consensus among the policy makers and academic economists that education is one of the most important policy instruments to make the playing field level for children from the poor socio-economic background, and moderate the inequality generated by market reform. It is thus important to understand potential disadvantages faced by children from a poor socio-economic background in attaining the education and skills required in an increasingly globalized and skill-based labor market.

The economics literature on intergenerational educational mobility has focused on parental education as the relevant indicator of family background for understanding intergenerational linkages (see Bjorklund and Salvanes (2011) for a recent survey, and on China, see, among others, Knight et al. (2013), Sato and Li (2007), Emran and Sun (2011)). This emphasis on parental education is eminently appropriate when the goal is to estimate the causal effects of parental education on children's schooling (for a recent survey, see Holmlund et al. (2011)). However, this approach may be less than satisfactory in understanding intergenerational transmission of economic status, where the focus is on the role of family background in generating and sustaining educational inequality. Because it implicitly assumes that parents' education is effectively a sufficient statistic for family background relevant for children's education, and thus ignores the role of parents' occupation, regarded as the most important indicator of socio-economic status in a large literature on mobility in Sociology (see, for example, Grusky and Cumberworth (2010)). ${ }^{3}$ This omission seems

\footnotetext{
${ }^{2}$ In the 17th congress, the Chinese Communist Party instructed the party officials and cadres to place "harmonious society" at the top of agenda (Peoples Daily, Sept 29, 2007).

${ }^{3}$ Grusky and Cumberworth (2010) note: "...sociologists typically carry out analyses of intergenerational mobility in terms of occupations....., because occupations are so deeply institutionalized in the labor market, they serve as a powerful omnibus indicator of life conditions and chances."
} 
especially surprising in the context of villages in developing countries, given substantial evidence that non-farm occupations yield higher income, and non-farm income may be an important source of increasing inequality in rural areas (for recent surveys see, for example, Lanjouw and Feder (2001), Haggblade et. al. (2007), and on rural China see Benjamin et. al. (2008), Rozelle (1996, 1994), Knight et, al. (2010b), Yang and Yuing (2002), Mcguire et al. (1996)). ${ }^{4}$

The rural economy in China has experienced fundamental structural transformation over the reform period, with impressive growth in non-farm employment and output in the recent decades. The share of non-farm sector in household income in rural China increased from 22 percent in 1980 to 51 percent in 2001. ${ }^{5}$ There are potential interactions between education and non-farm occupations, which may exacerbate inequality. Consistent with Schultz's view that education equips people to deal with disequilibria, the evidence indicates that educated families in rural China were the first responders to the incentives created by household responsibility system and related reforms, and were able to take advantage of the growing non-farm sector to reap higher income (Yang, (2004), Yang and Yuing (2002)). Positive feedbacks among education, nonfarm occupation, and income may lead to a bifurcation where the children born into parents with higher education and nonfarm education enjoy a clear and cumulative advantage in education, while the children of uneducated farmers are trapped in low educational attainment. ${ }^{6}$

A broader conception of parental economic status that combines both parental education and occupation is also desirable from a "measurement perspective", because it provides a better measure of permanent income of parents. This is especially valuable given the inadequacies of income data in most of the developing countries. There is a large

\footnotetext{
${ }^{4}$ Parents' education and occupation are also among the most salient 'circumstances' in the related but distinct literature on 'inequality of opportunity'. For recent contributions in that literature see, for example, Brunori, Ferreira, and Peragine (2013), and Asadullah and Gaston (2012).

${ }^{5}$ See National Bureau of Statistics of China, Statistical Year Book, 2003.

${ }^{6}$ From this perspective, it is surprising that intergenerational occupational mobility from agriculture to non-farm occupations in rural areas of developing countries has attracted little attention in development economics. The only exception we are aware of is Emran and Shilpi (2011) which provides evidence on intergenerational linkages in non-farm participation in Nepal and Vietnam.
} 
and mature economic literature on intergenerational mobility in developed countries which deals primarily with the persistence in incomes across generations, with a special focus on the link between fathers and sons (for recent reviews, see Solon (1999) and Black and Devereux (2011)). An important lesson from this extensive literature which partly motivates our analysis is that income data available from cross-section household surveys or short panels yield unreliable estimates of intergenerational persistence which are severely biased downward (see Solon (1992), Mazumder (2005), Atkinson et al. (1983); Solon (1992); Zimmerman 1992)). It is extremely difficult, if not impossible, to find long-term panel data on both parents' and children's income in developing countries. Income data are especially prone to measurement error in villages in developing countries due to large informal and non-market economy (Deaton (1997)). A natural alternative is to use two most salient indicators of parents' socio-economic status routinely available in standard household surveys: education and occupation. ${ }^{7}$ The focus of this paper is on the role of family background as measured by parental education and occupation in the evolution of educational inequality among children in rural China across three generations (two intergenerational links: grandparents-parents, and parents-children). We use data from the 2002 round survey of the Chinese Household Income Project (CHIP) for our empirical analysis. ${ }^{8}$ An important advantage of the CHIP 2002 survey is that it is possible to address the coresidency bias in a credible manner for both the grandparents-parents and the parents-children samples (please see the discussion in the data section).

We develop a research design in terms of two binary indicators of parents' economic status: higher education $\left(\left(E_{i}^{p}=1\right)\right.$ if at least one parent of child $i$ has education more than

\footnotetext{
${ }^{7}$ Many household surveys in developing countries contain income information only for a single year (the survey year). As shown by Mazumder (2005) in the context of USA, income data for a period of a decade and half may be required to tackle the measurement error. Since measurement error is likely to be a much more severe problem in income data from developing countries, one probably needs data over a longer period of time.

${ }^{8} \mathrm{~A}$ reader might wonder whether it would be best to include all of the available indicators of parental socio-economic status and create an index using statistical techniques such as principal components. It is, however, difficult to interpret the estimates based on a principal component index, because ranking according to, for example, the first principal component lacks any clear economic content.
} 
a threshold such as primary schooling), and non-farm occupation $\left(O_{i}^{p}=1\right.$, if at least one parent's primary occupation is non-farm), and split the sample into four mutually exclusive groups (see Figure (1) below). ${ }^{9}$ This framework allows us to use appropriate subsamples as "treatment" and "comparison" groups to explore a set of important questions related to the role of family background in children's schooling using recently developed matching and propensity score weighted estimators (Millimet and Tchernis (2013), Huber et al. (2013)). ${ }^{10}$

First, we provide evidence of substantial heterogeneity. Focusing on the children's generation, the standard specification with parental education as the sole indicator of economic status shows that a child of a parent with more than primary schooling gains about a year of more schooling. But our results reveal substantial heterogeneity across occupations within a given education group and across education levels within a given occupation group. For example, within the low education sub-sample, a son attains about 0.80 years of additional schooling when born into a non-farm household compared to a farm household, and the corresponding gain in schooling for a girl is about 0.60 years. Among the farming households, a child gains a one year of schooling when at least one parent has more than primary schooling. We find that the children from households with better educated and non-farmer parents are the "fortunate children". A child in this group attains 1.5 years of more schooling on average, and the gain in schooling can be close to three years for some children when parents have more than middle schooling and non-farm occupation. ${ }^{11}$ This provides a much richer texture of the roles played by family background across gender and generations, when compared to the standard analysis that relies exclusively on the parental education as the marker of socio-economic background.

\footnotetext{
${ }^{9}$ We focus on primary schooling as the education threshold to keep estimates comparable across three generations. The proportion of grandparents with of more than middle school is too small (4 percent) for any meaningful analysis. However, in a later section of the paper, we report estimates for parents-children sample using middle school as the relevant cut-off.

${ }^{10}$ Most of the existing analysis of intergenerational educational mobility in developing countries including China relies exclusively on the OLS estimator.

${ }^{11}$ The children from uneducated farming households constitute the comparison group. Among children with nonfarm parents and more than middle school education, the effects is stronger for sons; the MBNIPW estimate is 2.83 years of additional schooling. But the corresponding estimate is smaller for girls: approximately 1.9 years of additional schooling.
} 
Second, a comparison of the children in non-farm but low education households with the children in farm but high education households helps us to understand better the relative roles of family resources (income effect) and a human capital effect not mediated through income. This exploits the fact that the farm households with high education, in general, have much lower income compared to non-farm households with low education, and provides a simple test of the hypothesis that children's educational inequality is primarily a poverty problem in a rural economy. ${ }^{12}$ Our results show that children born into relatively high income households (low educated non-farm parents) do not enjoy any advantages compared to the poorer households (better educated farmer parents). The evidence also suggests that gender parity in the schooling of children in the reform period is achieved once at least one parent has more than primary schooling. This conclusion is robust across farm and nonfarm occupational categories, suggesting that gender bias may not be driven primarily by resource constraint.

Third, we analyze whether parental education and occupation are mutually complementary or substitutes in the production of educational attainment of children. The research design allows us to test whether children's schooling function is supermodular in parental education and occupation without imposing arbitrary functional forms. We find little evidence of complementarity between parental education and occupation in determining the schooling attainment of the children. In fact, our evidence indicates that, if anything, for boys in the reform era, parents' non-farm occupation may be a substitute for parents' education.

Fourth, a comparison of parents' and children's generations shows that for girls, the role of family background in schooling attainment remains largely unchanged across two generations, but for boys, family background has become more important. While grandparents' education and occupation played only a moderate role in fathers education, the

\footnotetext{
${ }^{12}$ In our parents-children sample, in 2002, per capita income is about 30 percent higher than that of the better educated farmer group. Unfortunately, there is no income data available for the grandparentsparents sample.
} 
effects of parental education and occupation have increased substantially for the sons, leading to a gender convergence in the effects of family background across different groups. A comparative analysis of parents' and children's generations is interesting because most of the parents completed schooling before the reform which allows us to compare and contrast the effects of family background in a socialist versus a more market oriented economy. ${ }^{13}$

\section{(2) Related Literature}

This paper contributes to a small but active literature on intergenerational economic mobility in developing countries. Recent contributions in this literature include, among others, Hertz et al. (2007), Binder and Woodruff (2002), Behrman et. al. (2001), Duncan (1996), Lillard and Willis (1994), Lam and Schoeni (1993), Daude (2011), Asadullah (2012), Emran and Shilpi (2011, 2012), Bossuroy and Cogneau (2013), Maitra and Sharma (2010)). To the best of our knowledge, there is no paper in the economics literature on developing countries including China that analyzes the role of the structural change from agriculture to nonfarm in intergenerational educational mobility in rural areas.

Our analysis is obviously closely related to multiple strands of literature on China: educational inequality, economic mobility, rural nonfarm economy and the interactions among them. A large part of the literature on inequality in China focuses on spatial differences between coastal and interior regions, and across rural and urban areas (see, among others, Fleisher et al. (2010), Kanbur and Zhang (2005), Chen and Fleisher (1996), Knight and Song (1999), Park (2008)). For insightful analysis of inequality in post-reform period see, among others, Shi et al. (2013), Benjamin et al. (2008), Gustafsson et al. (2008), Khan et al. (1999), Ravallion and Chen (1999), Griffin and Zhao (1993). Benjamin et al. (2005) provide an in-depth and comprehensive analysis of the evolution of inequality during the transition in rural China. An important finding in Benjamin et al. (2005) which is partly responsible for our focus on non-farm occupations is that non-farm income has

\footnotetext{
${ }^{13}$ As we discuss later, the farm and nonfarm distinction carries different meanings before and after the reform, because the policies implemented during the Maoist era (in particular the cultural revolution) were aimed at enhancing the social position of peasants and improving educational mobility of their children (see, among others, Hannum and Xie (1994), Sato and Li (2007), and Hannum et al. (2008)).
} 
played an important role in worsening income distribution in rural China since 1995.

The effects of non-farm opportunities on educational attainment of rural children have been analyzed by de Brauw and Giles (2008) with a special focus on migration; they show that the urban migration opportunities affect schooling attainments of poor rural children adversely. The structural change within the rural economy from farm to non-farm in rural China has been the focus of a substantial literature (see, for example, Nyberg and Rozelle (1999), Mukherjee and Zhang (2007), de Baruw et. al. (2012)). According to the estimates reported in de Baruw et al. (2012), the rural economy in China has experienced significant structural change during the reform period; from 1991 to 2004 the proportion of households reporting positive time allocation to farm activities fell from 89 percent 70 percent, and the household engaged in farm work, the average total hours devoted to farm work declined dramatically from 3,528 in 1991 to 1,756 in 2004.

Although the research on economic mobility in China has focused primarily on urban areas (see, for example, Deng et al. (2013), Gong et al. (2012), Gou and Min (2008)), there is a small but growing strand that focuses on rural China. Some of the recent contributions closer to our interest analyze intergenerational educational mobility in rural China; see, for example, Knight et al. (2013), Sato and Li (2007), Emran and Sun (2011). However, all of the available economic research on educational mobility in developing countries including China relies on the standard single factor representation of parents' economic status, where parents' education is the sole indicator. ${ }^{14}$

We also take advantage of a rich literature on educational policy and returns to education in China to interpret our results (see, among others, Hannum and Park ed. (2007), Hannum et. al. (2008), Fleisher and Wang (2005), Hannum and Xie (1994), Debrauw and Rozelle (2008), de Brauw and Giles (2008), Fang et. al. (2012), Tsang (2001)). The recent literature on intergenerational educational mobility identifies a close link between an increase in returns to education and intergenerational educational persistence. For example,

\footnotetext{
${ }^{14}$ For an interesting analysis of and evidence against the single factor model of intergenerational income mobility in the context of USA, see Lefgren et al. (2012).
} 
in the context of USA, Aaronson and Mazumder (2008) and Mazumder (2012) find that the periods with high returns to education are also characterized by high intergenerational persistence (i.e, low mobility). ${ }^{15}$ The evidence from the literature on China shows that while private returns to education was very low before and during the early period of the economic reform, the returns have been increasing over the reform era (Fleisher and Wang (2005), de Brauw and Rozelle (2008), Hannum et al. (2008)). The recent estimates by Fang et al. (2012) show that the over-all returns to one more year of schooling between 1997 and 2006 is about 20 percent for individuals 35 years of age or younger in 2000. The available evidence also indicates that the returns to education is higher in non-farm activities and there is a gender penalty against girls (de Brauw and Rozelle (2008)). The literature on the changes in educational policy in rural China and its implications for inequality is rich with many interesting and insightful contributions (see, for example, Hannum and Xie (1994), Hannum and Park (2007), Tsang (2000), Ma and Ding (2008)). Hannum and Xie (1994) discuss the role played by the conflicting objectives of efficiency and equity in changing educational policy in China, before and after the reform. The implications of fiscal decentralization starting from mid 1980s for educational inequality has been underscored by many authors (see, for example, Brown and Park (2002), Hannum and Park (2007), Hannum et al. (2008)).

\section{(3) Conceptual and Empirical Framework}

A large literature on intergenerational educational mobility, both in developed and developing countries, analyzes the persistence in educational attainment across generations, where parents' education is used as a measure of economic status. The standard regression specification used almost universally is as follows:

$$
E_{i}^{c}=\alpha_{0}+\alpha_{1} E_{i}^{p}+\Gamma^{\prime} X+\varepsilon_{i}
$$

\footnotetext{
${ }^{15}$ For the relevant theory underlying the link between increasing returns and lower mobility, see, for example, Solon (2004).
} 
where $E_{i}^{c}$ is the years of schooling of children $i, E_{i}^{p}$ is an indicator of parental education of child $i, X$ is a vector of exogeneous control variables. A substantial body of evidence based on this or variant of this specification shows that parental education is strongly correlated with children's education. However, there are at least two features of the above specification which requires scrutiny. First, it is implicitly assumed that parent's education is effectively a sufficient statistic for the socio-economic status a child is born into, and second, the effect of parental education is usually assumed to be constant for all households. When one allows for heterogeneous effects, $\alpha_{1}$ captures an average of the effects.

There is a parallel literature that focuses on intergenerational occupational mobility, the corresponding regression specification is:

$$
O_{i}^{c}=\gamma_{0}+\gamma_{1} O_{i}^{p}+\Theta^{\prime} X+\epsilon_{i}
$$

where $O_{i}^{c}$ is an occupation dummy (it takes on the value of 1 when children's occupation is non-farm in our analysis), and $O_{i}^{p}$ is the corresponding occupation dummy for parents (see, for example, Emran and Shilpi (2011)).

The recent economics literature on intergenerational mobility in developing countries, has focused on education and occupational linkages separately, largely ignoring any possible cross-effects. Since parents' occupational choices depend on their education, among other things, the standard specification as in equation (1) partly captures the effects of occupation on children's education. In fact, there is a substantial literature that finds a significant positive effect of education on the probability of non-farm participation in villages in developing countries (Lanjouw and Feder (2001)). It is, however, important to appreciate that educational attainment of children may depend on parental occupation in rural areas (agriculture vs. non-farm), even after the 'total effects' (i.e., total derivative) of parental education are accounted for. First, parents engaged in non-farm occupation are likely to have higher permanent income, even when their educational attainment is 
low. ${ }^{16}$ The role of non-farm occupations may have become increasingly important after the fiscal decentralization in China, because of the importance of fees collected by the schools, especially in poor counties (Tsang (2001), Brown and Park (2002)). Second, the returns to education is higher in non-farm sector compared to agriculture in most of the developing countries. The expected higher returns to education leads to higher investment in children's education, given the cost, and thus strengthen the link between parental economic status and children's schooling.

Once we acknowledge that both parental education and occupation are potentially important for children's educational attainment, an immediate question arises about the nature of interaction between them: are they complementary or substitutes? ${ }^{17}$ These considerations may lead one to the following specification of the effects of parental education and occupation on children's education:

$$
E_{i}^{c}=\beta_{0}+\beta_{1} E_{i}^{p}+\beta_{2} O_{i}^{p}+\beta_{3}\left(E_{i}^{p} \times O_{i}^{p}\right)+\Upsilon^{\prime} X+v_{i}
$$

In this framework, $\beta_{3}>0$ implies complementarity between parental education and occupation, while $\beta_{3}<0$ implies substitutability, and $\beta_{3}=0$ suggests separability.

While the above specification is intuitive and useful, it suffers from some limitations. First, we have to estimate three parameters $\left(\hat{\beta}_{1}, \hat{\beta}_{2}\right.$, and $\left.\hat{\beta}_{3}\right)$ in a single specification, which precludes the use of a rich array of econometric approaches recently developed for a binary treatment, for example, matching and propensity score weighted estimators (Busso et al. (forthcoming). Second, it is restrictive in testing potential complementarity, because it imposes linearity in parameters assumption. To get around these limitations, we split the sample in four mutually exclusive groups in terms of binary indicators of parents'

\footnotetext{
${ }^{16}$ In the context of rural China, non-farm occupations are positively correlated with higher household income in the post reform period (see the evidence in Table 1). But it may not be the case for the pre-reform period, especially during cultural revolution. Unfortunately, we do not have any income information for the grandparents.

${ }^{17}$ The linear specification that ignores possible interactions is almost universal in the literature on intergenerational mobility, both in economics and sociology.
} 
educational and occupational status:

$D_{i}^{00} \equiv\left(E_{i}^{p}=0, O_{i}^{p}=0\right), D_{i}^{01} \equiv\left(E_{i}^{p}=0, O_{i}^{p}=1\right) ; D_{i}^{10} \equiv\left(E_{i}^{p}=1, O_{i}^{p}=0\right), D_{i}^{11} \equiv\left(E_{i}^{p}=1, O_{i}^{p}=1\right)$

This $2 \times 2$ education and occupation classification allows us to use appropriate groups as "treatment' and "comparison" in a binary treatment set-up where there is only one parameter of interest.

One can also re-specify equation (3) above as follows which can be estimated by OLS:

$$
E_{i}^{c}=\theta_{0}+\theta_{1} D_{i}^{01}+\theta_{2} D_{i}^{10}+\theta_{3} D_{i}^{11}+\Pi^{\prime} X+\varepsilon_{i}
$$

where $D_{i}^{00}$ is the omitted category (the "comparison" group). The parameters of equations (3) and (4) are related as below:

$$
\beta_{1}=\theta_{1} ; \beta_{2}=\theta_{2} ; \beta_{1}+\beta_{2}+\beta_{3}=\theta_{3} .
$$

Note that in this framework, complementarity implies the following inequality: $\theta_{3}>$ $\left(\theta_{1}+\theta_{2}\right)$. Intuitively the intersection has a stronger effect than the union, i.e., the sum of individual effects.

Since non-farm occupations, in general, yield higher permanent income in developing countries, a reasonable ranking of the four different groups in terms of both parental income and human capital is:

$$
D_{i}^{11} \succ\left[D_{i}^{01}, D_{i}^{10}\right] \succ D_{i}^{00}
$$

i.e., we can rank the groups, except for the two groups in the middle in relation to each other. The relative ranking of $D_{i}^{10}$ and $D_{i}^{01}$ is not unambiguous, as higher education is also correlated with higher income. In the context of most developing countries, it is reasonable to posit that $D_{i}^{01} \succ D_{i}^{10}$ if one is interested in a measure of permanent income, because the non-farm households enjoy higher income compared to the farm households 
even when the farm households are better endowed in terms of human capital (education). We discuss later evidence on per capita income of parents in our data set which confirms this ranking for the parents-children sample, but there is no income information available for the grandparents. ${ }^{18}$ Note, however, that if the focus is on the transmission of parental human capital alone, then the appropriate ranking is reversed: $D_{i}^{01} \prec D_{i}^{10}$. This reversal of the rankings of these two groups in terms of parental income and education provides us with an excellent opportunity to study the relative roles of family resources compared to parental education as a direct influence over and above the income effect. Under the null that low schooling attainment is due to parents' low income alone, parents education would matter only in so far as it affects income. ${ }^{19}$ In this case, we would expect that the effect of being born into a low education non-farm household $\left(D_{i}^{01}\right)$ should boost children's schooling much more than it would for a child born into a farm household with high education. In contrast, if the evidence shows that the effects of having higher educated farmer parents is higher compared to that of low educated non-farmer parents, this would imply that parental education is more salient, and has important effects not mediated through income.

The research design with four mutually exclusive groups also enables us to implement an approach to potential complementarity between parental education and occupation which does not depend on the parametric specification as in equation (3) above. To fix ideas, consider the general specification of children's years of schooling:

$$
E_{i}^{c}=F\left(E_{i}^{p}, O_{i}^{p}, X\right)
$$

In this formulation, parental education and occupation are complementary only if the function $f($.$) is supermodular in E_{i}^{p}, O_{i}^{p}$ which implies the following cross-partial derivative

\footnotetext{
${ }^{18}$ As noted before, nonfarm occupational status of grandparents may not necessarily imply higher income in rural China before the reform.

${ }^{19}$ Understanding the role of parental income for children's education is the focus of a substantial literature; see, for example, Shea (2000), and Lefgren et al. (2012).
} 
(assuming twice differentiability):

$$
\frac{\partial^{2}}{\partial E_{i}^{p} \partial O_{i}^{p}} F(.)>0
$$

The advantage of our framework is that we can estimate a discrete analog of the above cross-partial derivative without assuming any functional form, if we exploit matching methods (see below for different econometric approaches). A specific approach implemented in this paper estimates the partial derivative $\frac{\partial}{\partial E_{i}^{p}} F\left(\right.$.) separately for the farm $\left(O_{i}^{p}=0\right)$ and nonfarm $\left(O_{i}^{p}=1\right)$ sub-samples using an appropriate matching method, and then estimates the discrete analog of the cross-partial effect as the difference between these two estimates. The recent econometric literature points out that estimating the cross-partial effects may not be straight-forward when the linearity (in parameters) assumption in equation (3) is not correct (Ai and Norton (2003), Greene (2005)). The estimates from our approach remain valid even when the linearity in parameters assumption is violated.

The available economics (and sociology) literature on intergenerational educational mobility in developing countries has relied almost exclusively on the OLS estimator. We use a number of alternative estimators suggested in the recent econometrics literature. This may be valuable for making some progress on two issues. First, to provide some evidence on the robustness of standard OLS estimates which impose strong functional form assumption and also ignores the problem of limited overlap between treatment and comparison groups. Second, it helps us take a first (small) step to causal interpretation of the estimates. It is, however, important to appreciate that our conclusions regarding the heterogeneity in (i.e., ranking of) the effects of parent's economic status across gender and different socioeconomic groups, and over time across grandparents-parents-children are unlikely to be driven by omitted genetic correlations in ability and preference which have been the focus of a large literature (see the discussion in Black and Devereux (2011)). Because there are no plausible reasons to expect the strength of genetic transmissions to vary significantly by gender, and it is virtually impossible for genetic correlations to change in any 
significant manner over the short span of three consecutive generations ((grandparentsparents-children).

We use two matching estimators, and also two estimators based on propensity score weighting. The matching estimators are: (i) bias corrected nearest neighborhood matching due to Abadie and Imbens (2002) (henceforth called 'A-I Matching'), and (ii) bias corrected radius matching (henceforth called 'BC-RM') due to Lechner et al. (2011). The two estimators based on propensity score weighting are: Normalized Inverse Propensity Score Weighted (NIPW) estimator due to Hirano and Imbens (2001) and Hirano et al. (2003), and the Minimum Biased estimator (MB-NIPW) proposed by Millimet and Tchernis (2013). ${ }^{20}$ There is substantial monte-carlo evidence in favor of these estimators for estimating causal effects with non-experimental data. Busso et al. (forthcoming) provide evidence that NIPW performs best among a large set of matching and propensity score estimators in estimating a binary treatment effect, and Huber et al. (2013) provide extensive evidence from empirical Monte-carlo that the BC-RM estimator due to Lechner et al. (2011) performs very well among a wide set of estimators. While NIPW reduce biases in the estimates compared to the OLS estimates by using appropriate weighting, the MB-NIPW estimator is especially useful, because it minimizes the biases arising from selection on unobservables. Millimet and Tchernis (2013) provide evidence that the MB-NIPW estimator is able to correct for some of the biases due to selection on unobservables and yield more reliable estimates of the causal effects when the conditional independence assumption fails. According to the Monte Carlo evidence reported by Millimet and Tchernis, the MB-NIPW estimator performs particularly well when the estimating equation suffers from omitted variables (such as omitted ability heterogeneity in educational attainment in our case). It is, however, important to appreciate that the advantage of MB-NIPW estimator in terms of causal interpretation comes with a price: the estimates are relevant for only a subset of the population defined by an interval around the bias minimizing propensity score of 0.05 . In other words, the estimates provide

\footnotetext{
${ }^{20}$ Millimet and Tchernis calls it MB estimator, but we prefer MB-NIPW because it underscores the fact that it is based on NIPW.
} 
local average treatment effect, similar to instrumental variables and regression discontinuity designs (for an extended discussion see Millimet and Tchernis (2013)). Thus the MB-NIPW estimates may be different from the other estimates, simply because they provide estimates for a sub population. While these different approaches are not designed to eliminate the correlation due to omitted heterogeneity, they can be useful as robustness checks on the OLS estimator almost exclusively used in the extant literature.

\section{(3) Data}

We use data from the 2002 round of Chinese Household Income Project (CHIP 2002) for our analysis. CHIP survey was collected by Chinese Academy of Social Science and a group of international researchers. The CHIP 2002 data have some important advantages for understanding the role played by family background in educational inequality in rural China. First, unlike the standard household surveys in many developing countries, we have the relevant data on education and occupation on three generations: grandparents-parentschildren. This allows us to understand whether the "children's generation" who grew up mostly during the reform period face significantly different educational opportunities compared to their parents who mostly grew up before the reform. Second, the data do not suffer from selection due to coresidency restriction standard in the household surveys in developing countries. ${ }^{21}$ For the parents generation (i.e., the grandparents-parents sample), the CHIP 2002 survey includes all of the grandparents irrespective of their residency. Thus the grandparents-parents sample does not suffer from any coresidency bias.

The sample on parents-children from the rural survey is also much richer compared to standard household surveys in many developing countries; because, in addition to the coresident children, the rural survey includes information on a significant proportion of the non-resident children. All of the non-resident children who had not been away for more than six months were included as household members. Among those who had been away

\footnotetext{
${ }^{21}$ The biases due to coresident sample in estimating the effects of parental characteristics on children's human capital have been widely noted; see, for example, Behrman (1999). For a recent analysis that shows that the standard regression estimates are significantly biased in a coresident sample, see Emran and Shilpi (2014).
} 
for more than six months, the survey counted a child as part of the household if he/she had significant economic connection with the household. ${ }^{22}$ The sampling procedure for the rural survey consists of two steps: first, sample villages are selected in each province, and then approximately 10 households are drawn from each village. The 2002 CHIP rural sample include 9200 households in 22 provinces.$^{23}$

Another important advantage of 2002 CHIP survey in this regard is that it also includes a migrant household survey of 2000 households that covers people residing in the urban areas with rural Hukou. This allows us to add a random sample of the individuals who may be missing from the rural survey because of migration. The final sample of 'parents-children' analysis thus ensures that the estimates are not subject to any significant coresident sample selection bias (for more details, see below).

\section{The Parents-Children sample}

Our parents-children sample is composed of two parts. The first subsample is extracted from the CHIP 2002 rural survey. Adult children in this paper are defined as individuals 18 years of age or older. We have a total of 5909 rural adult children-parents pairs, with adult children's age and education, parents' age, education and occupation identified.

The second parents-children subsample comes from the rural-urban migrant survey which captures the long-term migrants who have left their rural home and live in urban areas at the time of the survey. For the migrant survey, we are interested in household heads/spouses and their parents. We focus on the household heads/spouses 18 years of age or older. To capture the missing long-term migrants from the rural survey, we set four criteria for our migrant subsample. First, the household head/spouse must have an identified rural hukou. Second, they have stayed in the urban area for at least one year or longer by the time of the survey, which helps to identify the long-term rural migrants possibly missed in the rural survey. Third, they still have family member(s) living in the

\footnotetext{
${ }^{22}$ For an excellent discussion on the 2002 CHIP survey, please see Jin et. al. (2013).

${ }^{23}$ The 22 provinces are Beijing, Hebei, Shanxi, Liaoning, Jilin, Jiangsu, Zhejiang, Anhui, Jiangxi, Shandong, Henan, Hubei, Hunan, Guangdong, Guangxi, Chongqing, Sichuan, Guizhou, Yunnan, Shaanxi, Gansu, and Xinjiang.
} 
rural area. This ensures that the the families that are now fully urban are not included. Fourth, they did not have a strong economic tie with their original home back in the village. This is to avoid double counting (by both rural survey and migrant survey) and to prevent oversampling of the migrants. We use remittances sent back to the village as a measure of the strength of their relationship with the household of origin. We examine the distribution of their income and the remittances. The 80th percentile of the remittance rate is 20.8 percent of income. We then set the cutoff for the remittance rate at 20.8 percent and limit the migrants to those who had remitted less than 20.8 percent of their urban income back to rural home. The low remittance rate represents a weak economic tie and it is most likely that these rural migrants are not be captured in the original rural survey. Using the four criteria, we identified 1355 adult household heads/spouses and their parents along with the necessary information on household heads/spouses' age, education,and their parents' age, education and occupation. By reclassifying the migrants according to the province of their agricultural Hukou, and adding them to the rural survey sample, we have a total of 7264 valid children-parents pairs (5909 rural pairs plus 1355 migrant pairs). In our sample, most of the children (84 percent of daughters and 83 percent of sons) went to school after the reform was implemented in 1978. We thus can call them the 'children of reform'.

\section{Parents-grandparents}

In 2002 CHIP rural data, there is a specific module providing the information about the parents of household heads and spouses. Furthermore, this is the module for the complete parental information of the household heads and spouses, including the grandparents coresiding with the family, grandparents not co-residing, and also the grandparents who had passed away. We have identified 14777 parents-grandparents pair with the required information on parents' age and education, grandparents' age, education and grandparents. In our sample, most of the parents (95 percent of fathers and 92 percent of mothers) completed their schooling before the economic reform in 1978. Also, 59 percent of fathers education and 64 percent of mothers education were affected by cultural revolution. 


\section{(4) Empirical Results}

We begin with a discussion of the socio-economic characteristics of the different groups defined by the binary education and occupation classifications. Table $1 \mathrm{~A}$ presents the summary statistics for a set of economic and demographic characteristics of six different groups of households for the parents-children sample. Table 1B reports the corresponding estimates for four different groups for the grandparents-parents sample.

The evidence in Table 1 shows that the households in farm and low education (less than or equal to primary) group $\left(D_{i}^{00}\right)$ are characterized by unfavorable socio-economic characteristics including lowest education levels in both the parents' and children's generations, and lowest per capita income (income data are only for the parents-children sample). The non-farm and high education group $\left(D_{i}^{11}\right)$ occupies the other extreme, both parents and children have highest levels of educational attainment and also highest per capita income.

\section{(4.1) Parents Economic Status and Children's Schooling: Heterogeneous} Effects

In this section, we focus on the estimated effects of parent's economic status on children's schooling with a focus on potential heterogeneity across the four different groups defined in terms of parental education and occupation. We use a dummy for more than primary schooling for parental education for both generations, which ensures that the estimates across three generations are comparable. However, we also provide a set of estimates later for the parents-children sample using the middle school as the cut-off for the education dummy for parents, because about 60 percent of households have at least one parent with more than primary schooling. The choice of middle schools as a threshold is partly motivated by the findings in the recent literature that the probability of non-farm occupations in rural China is much higher for an individual with 9 years or more of schooling during the reform period (de Brauw and Rozelle (2008)).

\section{(4.1.A) Family Background and Schooling in Children's Generation}

We begin with the estimates of the effects of parents' occupational and educational 
status on the schooling of children (parents-children sample) when the education dummy is defined in terms of primary education as the cut-off. The estimates from alternative estimators (OLS, A-I Matching, BC-RM, NIPW and MB-NIPW) are reported in Table 2. We report estimates separately for daughters (panel A) and sons (panel B). All of the regressions include age and age squared of father, mother, and the child. ${ }^{24}$ The specification of the estimating equation is thus similar to that of Solon (1992). The first column reports the estimate of the effects of parents' education dummy alone, as is standard in most of the recent economics literature, i.e., it provides an estimate of the parameter $\beta_{1}$ in equation (1) above. This is a useful benchmark to assess the results from the $2 \times 2$ education and occupation research design. The last three columns in Table 2 report the estimates for the three different "treatment" groups: column 2 for the households with low education and non-farm parents (parameter $\theta_{1}$ ), column 3 for the high education and farming households (parameter $\theta_{2}$ ), and column 4 for the high educated and non-farm households (parameter $\left.\theta_{3}\right)$.

The OLS estimates in column 1 of Table 2 show that the average effects of parents' education on sons and daughters samples are similar in magnitude: having at least one parent with more than primary schooling increases schooling attainment by approximately one year for a child. These estimates, however, do not account for differences in parents' occupations, and can be interpreted as average effects in a model where the effect of parental education is heterogeneous across occupational categories. While the average is useful as a summary measure, these estimates also miss heterogeneity potentially important for understanding cross-sectional inequality. The estimates in the last three columns show that the average estimates do hide significant heterogeneity. The evidence shows that the apparent gender neutrality in the average effects in column (1) may primarily be driven by the two high education groups in columns (3) and (4). The effects of being born into a low educated nonfarm household are different across gender according to three of the

\footnotetext{
${ }^{24}$ As discussed in the data section above, 96 percent of household heads are male. We divide the sample into fathers and mothers by including the spouse of female headed households as fathers.
} 
estimators including OLS. The estimates from MB-NIPW in particular indicate that the gender gap may be large (90 percent higher for sons) for a segment of the households. ${ }^{25}$

A look at the last three columns in Table (2) shows that all of the coefficients across groups and estimators are statistically significant at the 10 percent level or lower, and also numerically substantial. This provides a clear answer to the question posed in the title of the paper: the children born into the low educated farmer parents (the comparison group) are in fact saddled with the lowest educational attainment among the four different groups.

The evidence also suggests that the heterogeneity across the other three groups is substantial. The educational attainment of children born into parents with similar education may vary significantly depending on parents' occupation, and vice versa. Having a parent with more than primary schooling provides an advantage of about 1.5 years of more schooling for a daughter, and about 1.7 years for a son, when at least one parents' primary occupation is non-farm. But the corresponding effects of better parental education among the farming households are much smaller: about 1 years of additional schooling irrespective of gender. Within the low educated subsample, having a non-farm parent increases schooling by about 0.60 year for daughters and by about 0.80 year for sons. These estimates bring into focus the importance of non-farm occupations in educational inequality which is masked by the average estimate in column (1). A comparison of the estimates across gender reveals interesting pattern: once at least one parent has more than primary schooling, the effects of family background do not show any appreciable gender bias (compare the estimates across sons and daughters in last two columns in Table 2). The flip side of this is that gender bias seem to persist with higher income when we focus on the subset of lower than primary schooled parents. The results thus suggest that gender bias in educational attainment may be primarily driven by parents' lack of education in so far as children who grew up during the reform period are concerned. ${ }^{26}$

\footnotetext{
${ }^{25}$ As noted earlier the MB-NIPW provides estimate for the treatment and comparison households around the bias minimizing propensity score of 0.5 . Our estimates use 0.25 radius, thus implying that 25 percent of the households on either side of propensity score of 0.5 are used for the estimation.

${ }^{26}$ This, however, is not true in grandparents-parents sample. Please see below.
} 
The ranking between the two intermediate groups (i.e., educated farmer parents vs. uneducated non-farmer parents) is also instructive: the children born into educated farmer parents seem to enjoy schooling advantage, irrespective of gender. For the daughters, all five estimators yield the same ranking: the point estimates for daughters born into more educated farmer parents with much lower per capita household income are substantially larger. The estimates for sons are similar according to four of the estimators, with the exception of the MB-NIPW estimates which suggest no significant difference. Compared to the estimates for daughters, the difference between the point estimates between these two groups for sons is much smaller.

\section{(4.1.B) Parents as Children: Estimates from the Grandparents-Parents Sam-} ple

Table 3 reports the estimates of the effects of grandparent's occupational and educational status on the schooling of parents (household head and spouse). We call the children in this generation 'parents' (mothers and fathers) and the parents are called 'grand-parents'. This helps keep track of three generations when we compare the effects of family background over time. Similar to Table 2, the education dummy is defined with primary schooling as the threshold.

The OLS estimates of $\beta_{1}$ in equation 1 reported in column (1) of Table 3 show that the average impact of grandparents education depends on the gender: it is higher for mothers (1.03) compared to that for fathers (0.76). This is in contrast to the apparent gender neutrality in the average effects in children's generation reported in column (1) of Table 2. All of the estimated effects for mothers are positive, numerically substantial and statistically significant at the 1 percent level, implying that, in the parents' generation, the girls (mothers) from the households with low educated farmer parents (i.e., grandparents) had faced the most disadvantages in schooling among the four different groups. Among the other groups, the mothers who were born into grandparents with both higher education and non-farm occupation have the highest schooling attainment; compared to the parents born 
into low educated farmer grandparents, they attain about 1.50 years of more schooling. This is a much larger effect compared to the average effect of grandparents education in mothers sample reported in column 1 (1.03). Interestingly, the advantage for a girl (mother) of being born into a business (non-farm) family with less than primary education is much smaller than the advantage derived from a household with better educated farmer grandparents. This strengthens the finding from the children's generation above about the importance of educated parents.

The estimated effects of grandparents' economic status are smaller in magnitude across the board for the fathers' sample when compared to the mothers' estimates. Thus the boys from poor economic background faced relatively less constraints on educational mobility in the parents' generation. The pattern of estimates across different groups for fathers is also different. First, the advantage from being born into low educated grandparents (as parents) involved in business is much smaller compared to the corresponding estimates for mothers (with low educated farmers' as the comparison group). Second, the difference between the estimates in last two columns is small, implying that birth into parents with better education and non-farm occupation did not confer any significant advantages for a son over the sons of farmer parents with better education. This is in contrast to the clear advantage for the non-farm higher educated group in the case of mothers, as discussed above.

(4.2) Do the Children of Reform Have More Educational Opportunities than Their Parents?

The results reported in Tables 2 and 3 provide a rich picture of the heterogeneous effects of family background on children's schooling attainment across gender and generations. As noted before, most of the parents completed their schooling before reform began in 1978, and most of the children completed their schooling during the reform period. In our grandparents-parents sample, 95 percent of fathers and 92 percent of mothers completed education before 1978. In contrast, 84 percent of daughters went to school after 1978, and 
the corresponding estimate for sons is 83 percent. A comparison between the grandparentparents and parents-children samples can thus provide us with useful evidence on the effects of market-oriented reform on children's educational opportunities in rural China.

The first point that comes across from a comparison of Tables 2 and 3 is that, for girls, the estimated effects of family background remained broadly similar across the two generations. The point estimates (OLS) of the average effects of parent's education on girls are very close to each others between mothers (1.03) and daughters (1.10) generations. For girls, the stubborn persistence is observed not only in the average estimates, interestingly the estimates from four out of five estimators in Tables 2 and 3 are similar in magnitude across the two samples (grandparents-mothers and parents-daughters). The estimates vary somewhat more according to the MB-NIPW estimator, but the magnitudes of the effects of family background paint a picture of stagnation for girls: the changes in economic and educational policies across the parents and children's generations seems to have made little difference to the roles played by family background in girls' education.

In contrast, the estimates for sons show an increase in the importance of family background over generations; according to the estimates in column (1), the average effects of parental education increased from 0.76 for fathers to 1.02 for sons, a substantial increase in magnitude (about 30 percent). The estimates for three groups in columns (2)-(4), however, suggest a more nuanced interpretation; while each group has experienced an increase in the impact of family background in the sons generation compared to their fathers, the magnitude of increase is the least for the children of better educated farmers. The sons born into the parents in non-farm occupation have gained in schooling attainment irrespective of the parental education level which suggests that higher income has played an increasingly important role in their educational attainment (recall that the low educated non-farm households have higher income than the better educated farmer households). This is consistent with the evidence that non-farm occupations have contributed significantly to the increase in rural inequality in 1990s (Benjamin et al. (2005)).

The increasing importance of parents' economic status in sons educational attainment 
probably reflects the consequences of a host of factors during the reform era. First, the evidence indicates that the returns to education is higher and increasing over the reform era, especially for the boys (de Baruw and Rozelle (2008), Fang et al (2012)). According to the theory of intergenerational economic mobility (see Solon (2004)), this is expected to strengthen the effects of family background on son's educational attainment as richer parents invest more in the education of their sons to take advantage of the rising returns. This investment in sons education may be reinforced by son preference and the reliance on a son for old age support which became more important with the market reform that dismantled the socialist safety net. The evidence reported by de Brauw and Giles (2008) shows that the urban migration opportunities opened up by the relaxation of Hukou restrictions from mid 1980s have affected adversely the schooling of poor children in rural areas. The role played by parental resources has increased in rural schools due to fiscal decentralization which started in mid 1980s and culminated in a comprehensive reform in 1994 (Hannum and Park (2002)). Fiscal decentralization compelled the schools in poorer counties to impose a varieties of fees on the households. Brown and Park (2002) report that the children were not allowed to attend the school if their parents had not paid the fees (see also the discussion in Hammum and Park (2007), and Tsang (2001)). ${ }^{27}$

The evidence that the effects of family background on girls did not change in any significant way from mothers' to daughters' generations may seem puzzling. The persistence in the effects imply that the strength and pattern of the effects of parents' educational and occupational status are driven primarily by factors that do not change easily over time

\footnotetext{
${ }^{27}$ Hannum and Park (2007) note "in the 1980s, the government decided to decentralize the administration and finance of the education. after the reform, in most regions, provincial, country, township and village governments took responsibility for schools at the tertiary, upper secondary, lower secondary, and primary levels, respectively (p.5). ...(in rich areas) decentralization has indeed allowed new resources to be mobilized in support of schooling, as wealthier and more entrepreneurial communities became capable of marshaling non-public resources that were previously unavailable to them(in poor area) however, there are vast financial challenges to extending compulsory education under such a system. In poor rural area, the ability to mobilize non-governmental resources is slim. Decentralization increased regional disparities in funding for schools, and also increased family educational expenditures required even for compulsory education, especially in poor areas where revenue-starved local government had no choice but to pass the burden of educational expenditures onto rural households. The disequalizing effects of changes in school finance were made worse by rising regional economic inequalities associated with market reform (p.6)."
} 
even in the face of dramatic changes in economic policies, significant income growth, and impressive poverty reduction. The literature on girls educational attainment in China emphasizes that whether a girl progresses through the school depends largely on her academic aptitude and grades, and may not be very sensitive to family economic conditions (Zhang, Kao, and Hannum (2007)). Since the distribution of academic abilities is persistent across generations, this may provide a partial explanation for the persistence across generation for girls found in Tables 2 and 3. Other factors that might have also played a role include (i) lower returns to education for girls, about 12 percent lower according to the estimates of de Brauw and Rozelle (2008), and (ii) low elasticity of parents' demand for girls schooling with respect to labor market returns, because the girls leave their parental home after marriage.

We also underscore an important implication of the results in Tables 2 and 3. The structural change in the rural economy from agriculture to non-farm activities has helped narrow the gender gap in education in parental generation, because it had a significant positive effect on mothers education, while the impact on the fathers was weak. The results on children's generation show that the pattern has changed: the effects of family background on sons have increased over the reform period to catch up with the effects observed for the girls, resulting in gender parity in the effects of family background, both in the mean effect and also across different groups.

\section{(5) Primary vs. Middle School as Parent's Schooling Threshold}

The results so far are based on a measure of parental education that uses primary schooling as the relevant cutoff. This is motivated by the fact that there are only a low proportion (4 percent) of grandparents with more than middle school (9 years of schooling). To have consistency across parents and children's generations, we thus had to settle on primary schooling as the relevant cut-off. However, in children's generation, at least one of the parents has more than primary schooling in 60 percent households. This implies that middle school may be a more discriminatory cut-off for the parents in the children's generation who went to school during the reform period. In this section, we report estimates 
of the effects of family background for the children's generation using middle school as the relevant threshold for parental education.

Using middle school (9 years schooling) as the relevant cut-off, however means that the sample of low educated (less than or equal to 9 years of schooling) farmers now includes the subset of farming parents with 7-9 years of schooling. If we use this subsample as the comparison group, then the estimates are not comparable to the estimates reported earlier in Tables 2 and 3 where the comparison group is composed if farmers with primary or less schooling. For the sake of consistency, we thus use the subsample of farmers with primary or less schooling as the comparison group, and estimate the effects of having at least one parent more than middle schooling for the farmer and non-farmer parents. The results are reported in Table $4 .^{28}$

The estimates in Table 4 are consistent with a priori expectations: the effects of having at least one parent with more than middle school education on the schooling of children are larger compared to the effects in Table 2 where the cut-off is primary schooling. Consistent with the results in Table 2, having higher educated non-farmer parents yields the most advantages. The estimated effects are larger in magnitude for sons compared to the daughters. The estimates show that having parents with more than middle school education and nonfarm job increases the schooling attainment by more than two years for a son; the estimate from MB-NIPW is close to three years (2.83).

(6) Choosing the Right Parents: Richer (but Uneducated) or Educated (but poor)?

An important question in the literature on educational inequality relates to the role played by resource constraint faced by poor parents. ${ }^{29}$ If the low schooling attainment of children from unfavorable socioeconomic background is primarily a poverty problem, then income transfers or policies that affect income of parents directly, or reduce the costs of

\footnotetext{
${ }^{28}$ We also estimated the effects using the subsample of farmers with 9 years or less schooling as the comparison group. The results are available from the authors.

${ }^{29}$ For recent contributions, see, among others, Shea (2000), and Lefgren et al. (2012).
} 
schooling such as free schooling would be sufficient to address schooling inequality. However, it is also possible that adequate resources is necessary but not sufficient for addressing schooling inequality across gender and different socio-economic groups.

Although the CHIP 2002 survey does not have data on grandparents' income, it provides good data on parents' income. In fact, the rural survey used in this paper reports household income for five years (including 2002). The income data in Table 5 show clearly that the households with non-farm occupation have higher income, given education. Among the low educated (primary or less schooling) households, per capita income of non-farmers is about 45 percent higher in 2002; and the corresponding estimate among the better educated (more than primary) households subsample is 40 percent higher income for non-farmer households. In contrast, gains in income from higher education within a given occupation category is much smaller, about 10 percent higher when at least one parent has more than primary schooling, in both farmers and nonfarmers subsamples. Interestingly, the low educated nonfarmers are significantly richer than the more educated farmers, their per capita income is 30 percent higher when education cut-off is primary schooling, and per capita income is 24 percent higher for the nonfarm households when middle schooling is the cut-off. Table 5 also reports average per capita income over 3 and 5 years period, and the ranking of four different groups is preserved. As noted earlier, we do not have data on grandparents income, and thus are unable to rank different groups according to income.

\section{Parents-Children Sample}

The estimates reported earlier in column (2) of Table 2 show that, among the households with primary or less educated parents, the children of nonfarmer parents enjoy significant advantages over the children of farmer parents (the omitted group), which suggests that the higher income of nonfarm occupations has a positive effect. Similar positive effect of non-farm occupation (and thus higher income) is also observed within the higher educated subsample: the point estimates for non-farm group (compare columns (3) and (4), Table 2) are consistently larger across all five different estimators irrespective of the gender of 
a child. A formal test of equality of the coefficients in columns (3) and (4) in Table 2 rejects the null convincingly across the board (see column (6) in Table 2). Similar results are also observed when we use middle school as the education threshold (please see Table 4). The evidence thus is convincing that parents' non-farm occupations increase children's schooling attainment, within a given parental education level. Given higher income of nonfarm households, this can be plausibly interpreted as evidence that parents income matters for children's education.

A natural question to ask at this point is then whether we can expect educational inequality to go down if there is income convergence among the households, even if there exists persistent differences in other households characteristics, especially parents' education. In other words, is reducing income inequality without reducing educational inequality among parents sufficient to equalize educational opportunities for the children. This question can be addressed fruitfully by comparing the low educated nonfarmer group with the better educated farmer group: is it better to have low educated richer parents than having more educated poor parents in so far as children's schooling is concerned? Under the null hypothesis that the binding constraint on children's educational attainment is low parental income (and parents education helps only in so far as it increases income), children born into low educated non-farm parents should achieve significantly higher schooling compared to the children from better educated farmer parents who have 30 percent lower per capita income (with a primary schooling cut-off). The point estimates in column (2) and (3) in Table 2 suggest the opposite: the estimated schooling gain is larger in magnitude for the children of better educated farmers. The advantages of having more educated poor parents (farmers) becomes stronger as the level of parental education increases from more than primary to more than middle school. This can be seen by comparing the children from farm households with more than middle schooled parents to the children from nonfarmer parents with less than primary schooling (compare columns 2 and 3 in Table 4).

The point estimates in Tables 2 and 4 thus provide strong evidence that having relative richer but lower educated parents does not give any advantage in terms of children's 
schooling attainment; if any thing, the estimates suggest that it might be better to have more educated poor farmer parents. Formal tests of equality of the coefficients in column (5) of Tables 2 and 4 show that the answer depends on the education level one considers. When we compare farmers with more than primary schooling with nonfarmers with less than primary (column (5) in Table 2), the effects are not significantly different for sons across all five estimators; for daughters, it is significant at the 10 percent according to OLS and NIPW estimators, but not according to the other three estimators. In contrast, the null of equality of coefficients is rejected by all five estimators for daughters when we compare the households with more than middle schooled farmer parents to those with less than primary schooler nonfarmer parents (column (5) in Table 4), even though the nonfarming households enjoy 24 percent higher income (per capita). For sons, estimates from four out of five estimators reject the null, only the MB-NIPW estimates are not significantly different. We note here that these two groups can be compared directly against each other, instead of using the children of low educated farmers as the common comparison group. The evidence from such an exercise is consistent with the conclusions based on Tables (2) and (4), and thus is omitted for the sake of brevity.

The evidence in Tables 2 and 4 thus strongly suggests that while increasing household income is associated with higher schooling attainment of children, having poorer but more educated parents may confer significant advantages compared to the children from richer but less educated households. Policies that reduce income inequality without addressing educational inequality thus may only have limited value in tackling educational inequality in the next generation.

\section{Grandparents-Parents Sample}

Although we do not have income data on grandparents to rank the groups in parents generation, for the sake of completeness, we compare the low educated non-farm group with the more educated farmer group. The point estimates in columns (2) and (3) in Table 3 show that the estimates are substantially larger for the parents born into more 
educated farmer grandparents. Tests of equality of the coefficients reported in column (5) show that, for boys, the null of equality is rejected by all five estimators, thus providing strong evidence that having more educated farmers was an important advantage for the fathers. For mothers, the null of equality is rejected by OLS and NIPW, but not by the other estimators, thus suggesting a weaker evidence.

\section{Comparison Across Generations}

A comparison of the parents' and children's generations in Tables 2 and 3 shows that the advantages of having educated farmer parents have become weaker during the reform era, especially for the boys. It may reflect two things. First, in parents generation, Maoist policies, especially Cultural Revolution, were aimed at improving the socio-economic opportunities of the children of peasants. In so far as this was successful, the children of educated farmer parents may have benefited (except for the children of intelligentia who were condemned as the enemy of the revolution during the cultural revolution). Second, in the children's generation, the higher income of the non-farm low educated parents may partly offset the disadvantages of lower education.

To provide some suggestive evidence on the second possibility, we use data on educational expenditure in CHIP 2002 rural survey to explore the issue of parents' investment in education across gender and different socio-economic groups. Note, however, that the education expenditure data are the expenditure incurred during the survey year on the children in school. In our rural survey data set, a household with one more boy spends an additional 488 Yuan on education, while the corresponding estimate for a girl is 352 Yuan, providing evidence that parents in general invest substantially more on a sons education (40 percent higher). Table 5 reports educational expenditure (per school aged child) for different groups. The first four groups correspond to the case when parents' education threshold is primary schooling and the last two to middle schooled parents in farm and nonfarm occupations. Two interesting observations come across immediately. First, better educated farmer parents spend more on the education of their sons and daughters when 
compared to the low educated nonfarmer parents. Although the difference in educational expenditure is not large when the 'high educated' is defined as the parents with more than primary schooling, the farmer parents spent substantially more when they have more than middle school education. This evidence is important because both the educated farmer groups (more than primary and more than middle) have significantly lower per capita income in 2002, which suggests that parents' education may be more salient in determining investment in children's schooling. Second, in the case of sons, parents with both better education and nonfarm occupation spend much more than the other two groups combined (more than primary as high education). The evidence thus does not support the conjecture that the low educated non-farmers spend relatively more on their children's education compared to the better educated poorer farmers. Note, however, that it is possible that compared to the earlier generation (grandparents), the parents with nonfarm occupations have much higher income in the reform period, and they also spend a lot more on children's education, thus closing the gap in both the financial investment in education and schooling attainment of children across these two groups.

(6) Parent's Education and Non-Farm Occupation: Substitutes, Complements or Separable?

This section reports evidence on the question whether there are possible interaction effects between parents' education and non-farm participation in producing children's schooling. As discussed in the conceptual and empirical strategy section above, there are some plausible a priori arguments in favor of the proposition that positive feedbacks between education and occupation may be important; education helps in finding better quality nonfarm jobs, and the expected returns to education for children may be higher as nonfarm jobs depend on network. Given higher income, the ability to finance education may also be higher for parents involved in non-farm activities. ${ }^{30}$ Another important factor is that edu-

\footnotetext{
${ }^{30}$ In our rural survey data for parents-children sample, among the low educated nonfarmers, 29 percent have high skilled nonfarm jobs, while among the parents with more than primary schooling 43 percent are engaged in skilled nonfarm economic activities.
} 
cated parents may be more effective in providing homework help and a home environment conducive to learning. However, it is also possible that resources are primarily substitutes for parental education in producing children's schooling. For example, higher income may enable the parents to buy the required educational inputs (such as better schools, tutors etc.). If the market for educational inputs is well developed, low educated non-farming parents may be able to offset some of the disadvantages of their own educational deficit (inability to help with homework, for example). Also, the relation between a parents education and the time devoted to children may not be monotonic. A highly educated parent may not have time to spend with his kids, especially given the higher price of labor in the market. This may create a negative correlation between direct educational inputs provided by a parent at home and his labor market opportunities, especially at the right tail of schooling distribution. Table 6 reports evidence on the existence and nature of interaction between parents education and non-farm occupation using alternative econometric approaches.

As noted in the empirical strategy section, a simple and widely used way to test the existence of an interaction effect is to estimate specification (3) in section 3 above, and the null of separability implies that $\beta_{3}=0$. But the limitation of this approach is that we have to rely on linearity in parameters assumption. Column (1) in Table 6 reports OLS estimates of the parameter $\beta_{3}$ in equation (3) which shows the effect of the interaction between two dummies: more than primary schooling and non-farm occupation in a linearin-parameters model. The evidence across gender and generations in general suggests the lack of a significant interaction effect; out of the four cases, only in the case of fathers the effect is statistically significant at the 10 percent level. More important, the sign is negative in this case, implying substitutability, rather than complementarity between grandparents education and non-farm occupation for fathers' schooling attainment. One might however have reservations about this simple test, as the conclusions may be affected by the linearity in parameters assumption.

We present a more robust test of possible complementarity by using the the methodology 
described earlier in section 3 above. Columns (2) and (3) in Table 6 provide estimates of the marginal effect of better education in two subsamples: parents in farming and in nonfarm occupation respectively. The last column reports the test of the null hypothesis that the marginal effects in columns (2) and (3) are equal, i.e, the null that there is no interaction effect. As noted before, this approach when estimated by matching methods does not depend on any functional form assumption. The evidence clearly shows that there is no evidence of complementarity between parental education and occupation in so far as children's schooling attainment is concerned. This conclusion is valid for both the parents-children and grandparents-parents samples. In fact, there are some evidence that in children's generation, especially for boys, non-farm occupation has become a substitute for parental education. This is consistent with the finding discussed above that the role played by higher income in the non-farm sector has assumed greater importance for the sons during the reform era.

We also check if there is complementarity between non-farm occupation and higher education (more than 9 years schooling). We estimate the effects of having more than 9 years of schooling (complete middle school) compared to the parents with less than or equal to primary schooling as the comparison. The results again show that there is little or no evidence of complementarity. The estimates are omitted for the sake of brevity and are available from the authors.

\section{Conclusions}

This paper provides evidence on the effects of parental economic status on children's educational attainment in rural China using a rich data set that covers three generations and does not suffer from coresidency bias. We develop a simple yet versatile research design that allows us to relax the single factor characterization of parental economic status standard in the economics literature on intergenerational educational mobility. We use two most salient markers of socio-economic status: parents' education and occupation to understand the effects of family background on children's schooling. We take advantage 
of recently developed matching and propensity score weighting estimators and provide evidence on (i) heterogeneous effects of family background, (ii) potential complementarity between parental education and non-farm occupation in promoting children's schooling, (iii) the role of parental resources vis a vis parental education as a direct influence on children's schooling, (iv) the evolution of intergenerational educational mobility across the pre and post reform generations.

The evidence shows that the current focus on the mean effect (intergenerational regression coefficient) misses substantial heterogeneity important for understanding educational inequality. The effects of family background vary significantly with parents' occupation within a given educational group, and across parents' education within a given occupation group. Our evidence indicates that once at least one parent has more than primary schooling, there is a gender convergence in the effects of family background in the children's generation most of whom went to school during the reform era. In contrast, among the low educated families, the parents' nonfarm occupation has a much larger positive effect on sons schooling, which is expected to widen the gender gap. The evidence thus indicates that gender bias may not be primarily a poverty problem. We also find that having nonfarm parents do not confer any advantages over the farmer parents if the farmers are relatively more educated, even though nonfarm households have significantly higher income. This suggests that income plays a secondary role to parental education in improving children's schooling.

Estimates of cross-partial effects without imposing arbitrary functional forms show that there is little evidence of complementarity between parental education and non-farm occupation in children's educational mobility which contradicts widely held perceptions. In fact, there is some evidence that nonfarm occupation may be a substitute for parents' education for sons educational attainment during the reform period. A comparison of parents and children's generations shows that for girls, the role of family background in schooling attainment remains largely unchanged across generations, but for boys, family background has become more important over the reform period. 


\section{References}

Aaronson, D and Bhashkar Mazumder (2008). "Intergenerational Economic Mobility in the United States, 1940 to 2000," Journal of Human Resources, University of Wisconsin Press, vol. 43(1).

Abadie, A and Guido W. Imbens, 2002. Simple and Bias-Corrected Matching Estimators for Average Treatment Effects, NBER Technical Working Papers 0283, National Bureau of Economic Research, Inc.

Agüero J. M. and Ramachandran M. (2010), "The Intergenerational Effects of Increasing Parental Schooling: Evidence from Zimbabwe, University of California, mimeo.

Ai, C. and E. Norton, "Interaction Terms in Logit and Probit Models, Economics Letters, 80, 2003, pp. 123-129.

Asadullah, M Niaz, 2012. "Intergenerational Wealth Mobility in Rural Bangladesh," Journal of Development Studies, Taylor Francis Journals, vol. 48(9), pages 1193-1208, September.

Asadullah, M. Niaz, and Yalonetzky, Gaston, 2012. Inequality of Educational Opportunity in India: Changes Over Time and Across States, World Development, Elsevier, vol. 40(6), pages 1151-1163.

Assaad R. and Saleh M. (2013), Does Improved Local Supply of Schooling Enhance Intergenerational Mobility in Education? Evidence from Jordan, Working Paper 788, The Economic Research Forum, Egypt.

Bossuroy, T and Denis Cogneau, 2013. Social Mobility in Five African Countries, Review of Income and Wealth, International Association for Research in Income and Wealth, vol. 59, pages S84-S110, October.

Behrman, J., A. Gaviria and M. Szekely (2001), Intergenerational Mobility in Latin America, Economía, Vol. 2 (1): 144.

Benjamin, D., L. Brandt, and J. Giles. 2005. The Evolution of Income Inequality in Rural China. Economic Development and Cultural Change 53 (4): 769824.

Benjamin, Dwayne, Loren Brant, John Giles, and Sangui Wang. 2008. "Income inequal- 
ity during China's Economic Transition", in Brandt, Loren; Rawski, G. Thomas, China's Great Transformation, Cambridge: Cambridge university press.

Binder, Melissa and Christopher Woodruff. 2002. Inequality and Intergenerational Mobility in Schooling: The Case of Mexico. Economic Development and Cultural Change, Vol. 50, Iss. 2, pp. 249-267.

Bjorklund A and K. Salvanes. (2011). Education and Family Background: Mechanisms and Policies, Handbook in the Economics of Education vol 3, EA Hanushek, S Machin and L Woessmann (es.), The Netherlands: North Holland, 2011, pp. 201-247.

Bjorklund A, Lindahl L, Lindquist M. (2010). What More Than Parental Income, Education and Occupation? An Exploration of What Swedish Siblings Get from Their Parents. B.E. Journal of Economic Analysis and Policy, 10 (1) (Contributions), Article 102.

Bjorklund A, Jantti, M, Lindquist, M. (2009). Family background and income during the rise of the welfare state: trends in brother correlations for Swedish men born 1932-1968. Journal of Public Economics, 93 (5-6), 671-680.

Björklund, Anders and Jäntti, Markus, 2012. How important is family background for labor-economic outcomes?, Labour Economics, Elsevier, vol. 19(4), pages 465-474.

Black, S. E. and P. Devereux (2011). Recent Developments in Intergenerational Mobility, Handbook of Labor Economics.

Black, S. E., P. Devereux and K. Salvanes (2005). The More the Merrier? The Effect of Family Composition on Children's Outcomes. The Quarterly Journal of Economics, 120(2), 669-700.

Blanden, J, P. Gregg, S. Machin (2005). Intergenrational Mobility in Europe and North America, Center For Economic Performance Report, April, 2005.

Blanden J., A. Goodman, P. Gregg, and S. Machin (2004). Changes in Intergenerational Mobility in Britain, in M. Corak (ed.) Generational Income Mobility, Cambridge University Press.

Blanden, J. P. Gregg and L. Macmillan (2008). Accounting for Intergenerational Per- 
sistence: Non-Cognitive Skills, Ability and Education, Economic Journal, 117, C43-C60.

Black, Sandra E., Paul J. Devereux and Kjell G. Salvanes (2005), Why the apple doesnt fall far: Understanding intergenerational transmission of human capital, American Economic Review 95: 437-449.

Brown, Phil and Albert Park, 2002, "Education and Poverty in Rural China", Economics of Education Review 21(6), 523-541.

Brunori, Paolo, Francisco Ferreira, and Vito Peragine. 2013. Inequality of Opportunity, Income Inequality and Economic Mobility. Some International Comparisons. Policy Research Working paper 6304. The World Bank, Washington, DC.

Busso, M., DiNardo J., McCrary, J. (forthcoming), New Evidence on the Finite Sample Properties of Propensity Score Reweighting and Matching Estimators, forthcoming in Review of Economics and Statistics.

Chen, J., and B. Fleisher, Regional Income Inequality and Economic Growth in China, Journal of Comparative Economics 22 (1996).

Daude, Christian. 2011. Ascendance by Descendants?: On Intergenerational Education Mobility in Latin America," OECD Development Centre Working Papers 297, OECD Publishing

Deaton, A (1997), The analysis of household surveys: A microeconometric approach to development policy. Oxford University Press.

Deng, Quheng, Gustafsson, Bjorn, Li, Shi. 2013. Intergenerational Income Persistence in Urban š China. Review of Income and Wealth.

de Brauw, Alan, Jikun Huang, Scott Rozelle, and Linxiu Zhang, 2013, Feminization of Agriculture with Chinese Characteristics, Journal of Development Studies, May 2013.

de Brauw, Alan, and Scott Rozelle, 2008, Reconciling the Returns to Education in Rural China, Review of Development Economics 12(1): 57-71.

De Brauw, Alan and John Giles (2006), "Migrant opportunity and the educational attainment of youth in rural China, IZA Discussion Paper No. 2326, Institute for the Study of Labor (IZA), Bonn, Germany. 
Duncan, Thomas 1996. "Education across Generations in South Africa",American Economic Review, American Economic Association, vol. 86(2), pages 330-34, May.

Emran, M. S and F. Shilpi (2011): Intergenerational Occupational Mobility in Rural Economy: Evidence from Nepal and Vietnam, Journal of Human Resources, issue 2, 2011.

Emran, M. Shahe Shilpi, Forhad, 2012. Gender, geography and generations : intergenerational educational mobility in post-reform India, Policy Research Working Paper Series 6055, The World Bank.

Fang, H., Eggleston, K., Rizzo, J., Rozelle, S. and Zeckhauser, R.J. (2012). The returns to schooling: Evidence from the 1986 compulsory education law. NBER Working Paper 18189 .

Fleisher, B., Li, H. and Zhao, M. Q. 2010. Human Capital, Economic Growth, and Regional Inequality in China Journal of Development Economics, 92, 215 - 231.

Fleisher, Belton M. and Wang, Xiaojun, 2005. "Returns to schooling in China under planning and reform," Journal of Comparative Economics, Elsevier, vol. 33(2), pages 265277, June.

Gong, Honge, Andrew Leigh and Xin Meng, 2012, "International income mobility in urban China, Review of Income and Wealth, Vol. 58, No. 3, pp. 481503.

Greene, W (2005), Testing Hypotheses About Interaction Terms in Nonlinear Models, NYU.

Griffin, Keith and Renwei Zhao. 1993. The Distribution of Income in China. St. Martin 's Press, New York, NY10010

Grusky, D and E. Cumberworth (2010), "A National Protocol for Measuring Intergenerational Mobility?", Stanford University.

Gustafsson, Bjorn, Li Shi and Terry Sicular. 2008. Inequality and Public Policy in China. Cambridge University Press, New York, NY, USA

Haggblade, Steven, Hazell, Peter B.R. and Reardon, Thomas (Editors). 2007. Transforming the Rural Nonfarm Economy. Baltimore: Johns Hopkins University Press.

Hannum, Emily and Albert Park. 2002. "Educating China's Rural Children in the 21st 
Century." Harvard China Review, 3(2): 8-14.

Hannum, E, Behrman, J., M. Wang, and J. Liu (2008): Education in the Reform Era, in Brandt and T. Rawski Ed: China's Great Economic Transformation, Cambridge university Press.

Hannum, Emily and Albert Park. 2007. Education and Reform in China. Routledge.

Hannum, E and Y. Xie (1994), "Trends in Educational Gender Inequality in China: 1949-1985", Research in Social Stratification and Mobility, Vol. 13.

Hertz Tom, Tamara Jayasundera, Patrizio Piraino, Sibel Selcuk, Nicole Smith and Alina Veraschagina. 2007. The Inheritance of Educational Inequality: International Comparisons and Fifty-Year Trends. The B.E. Journal of Economic Analysis and Policy (Advances), 7(2), Article 10.

Hirano, K. and Imbens, G.W. (2001), Estimation of Causal Effects using Propensity Score Weighting: An Application to Data on Right Heart Catheterization, Health Services and Outcomes Research Methodology, 2, 259-278.

Hirano, K., G.W. Imbens, and G. Ridder (2003), Efficient Estimation of Average Treatment Effects using the Estimated Propensity Score, Econometrica, 71, 1161-1189.

Holmlund H., Lindahl M. and Plug E. (2011), "The Causal Effect of Parents' Schooling on Children's Schooling: A Comparison of Estimation Methods", Journal of Economic Literature.

Huber, Martin, Lechner, Michael and Wunsch, Conny, 2013. "The performance of estimators based on the propensity score," Journal of Econometrics, Elsevier, vol. 175(1), pages $1-21$.

Jin, Song, Terry Sicular, and Yue Ximing. 2013. The 2002 and 2007 CHIP Surveys Sampling, Weights, and Combining the Urban, Rural, and Migrant Samples. In the book Rising Inequality in China: Challenges to a Harmonious Society, edited by Li Shi, Hiroshi Sato, and Terry Sicular, West Nyack, NY, USA: Cambridge University Press.

Kanbur, Ravi and Xiaobo Zhang (1999). Which Regional Inequality? The Evolution of Rural-Urban and Inland-Coastal Inequality in China from 1983 to 1995, Journal of 
Comparative Economics v27, n4 (December 1999): 686-701.

Kanbur, Ravi., and Xiaobo Zhang, Fifty Years of Regional Inequality in China: A Journey through Revolution, Reform, and Openness, Review of Development Economics 9 (2005), 87106 .

Khan, Azizur Rahman, Keith Griffin and Carl Riskin (1999). "Income Distribution in Urban China during the Period of Economic Reform and Globalization, American Economic Review v89, n2 (May 1999): 296-300.

Khan, Azizur Rahman and Carl Riskin. 2001. Inequality and Poverty in China in the Age of Globalization, New York: Oxford University Press.

Knight, John and Lina Song. 1993. The Spatial Contribution to Income Inequality in Rural China, Cambridge Journal of Economics 17: 195-213.

Knight, John and Lina Song (1999). The Rural-Urban Divide. Economic Disparities and Interactions in China, Oxford: Oxford University Press.

Knight, John, Li Shi and Deng Quheng. 2010. Education and the Poverty Trap in Rural China: Closing the Trap. Oxford Development Studies, 38:1, pp. 1-24

Lechner, M., Miquel, R. and C. Wunsch (2011): Long-Run Effects of Public Sector Sponsored Training in West Germany, The Journal of the European Economic Association 9, 742-784.

Lefgren, L, Matthew J. Lindquist and David Sims, 2012. "Rich Dad, Smart Dad: Decomposing the Intergenerational Transmission of Income," Journal of Political Economy, University of Chicago Press, University of Chicago Press, vol. 120(2), pages 268 - 303.

Li, Shi, Luo Chuliang, Wei Zhong, and Yue Ximing. 2008. The 1995 and 2002 Household Surveys: Sampling Methods and Data Description. In the book Inequality and Public Policy in China, edited by Bjorn Gustafsson, Li Shi, and Terry Sicular, Cambridge University Press, New York, NY, USA, page 337

Lillard, Lee and Robert Willis. 1995. Intergenerational Educational Mobility, Effects of Family and state in Malaysia. The Journal of Human resources, Vol. (29), pp 1126-1166. Lam, David, and Robert F. Schoeni. 1993. Effects of Family Background on Earnings 
and Returns to Schooling: Evidence from Brazil. Journal of Political Economy 101(4):710 40 .

Lanjouw, Peter, and Gershon Feder. 2001. Rural Nonfarm Activities and Rural Development. Rural Strategy Background Paper \# 4, World Bank.

Ma, Guiping and Mingqiang Ding. 2008. The Evolution of Basic Education Policy in Rural China after the Reform (in Chinese). Journal of Suihua University, Vol. 28 (Aug), pp 7-9.

Maitra, P and A. Sharma (2010), "Parents and Children: Education Across Generations in India", Working paper, Monash University.

Mazumder, Bhashkar (2005): Fortunate Sons: New Estimates of Intergenerational Mobility in U.S. Using Social Security Earnings Data, Review of Economics and Statistics, May, 2005.

Mazumder, Bhashkar (2012). Is intergenerational economic mobility lower now than in the past?, Chicago Fed Letter, Federal Reserve Bank of Chicago, issue April.

McGuire, William, Fleisher, Belton and Sheldon, Ian M., 2007. "Off-Farm Employment Opportunities and Educational Attainment in Rural China," China's Agricultural Trade: Issues and Prospects Symposium, July 2007, Beijing, China, International Agricultural Trade Research Consortium 55029, International Agricultural Trade Research Consortium.

Millimet, Daniel and Rusty Tchernis. 2013. Estimation of Treatment Effects Without An Exclusion Restriction: With an Application to the Analysis of the School Breakfast Program. Journal of Applied Econometrics, John Wiley Sons, Ltd., vol. 28(6), pages 982-1017, 09.

Mukherjee, Anit and Zhang, Xiaobo, 2005. "Rural non-farm development in China and India," DSGD discussion papers 24, International Food Policy Research Institute (IFPRI).

Nyberg, Albert, and Scott D. Rozelle, 1999, Accelerating Chinas Rural Transformation, World Bank, Washington D.C.

Park, Albert. (2008), "Rural-Urban Inequality in China, in Shahid Yusuf and Karen Nabeshima, eds. China Urbanizes: Consequences, Strategies, and Policies (Washington, 
D.C.: The World Bank), 2008.

Picketty, Thomas. 2014. Capital in the Twenty-First Century. Harvard University Press. ISBN 067443000X

Ravallion, Martin and Shaohua Chen (1999). When Economic Reform Is Faster Than Statistical Reform: Measuring and Explaining Income Inequality in Rural China, Oxford Bulletin of Economics and Statistics v61, n1 (February 1999): 33-56

Rozelle, Scott. 1994. Rural Industrialization and Increasing Inequality: Emerging Patterns in China's Reforming Economy. Journal of Comparative Economics, Vol. 19, Iss. 3, pp. 362-391

Sato, Hiroshi and Shi Li. 2007, Class origin, family culture, and intergenerational correlation of education in rural China. IZA Discussion Paper series No. 2642, Institute for the Study of Labor (IZA), Bonn, Germany

Solon, Gary, 1992. "Intergenerational Income Mobility in the United States, American Economic Review, American Economic Association, vol. 82(3), pages 393-408, June.

Solon, G (1999), "Intergenerational Mobility in the Labor Market," in O. Ashenfelter and D. Card eds Handbook of Labor Economics, Vol 3A, Elsevier Science, North-Holland, Amsterdam.

Solon, Gary (2004). "A Model of Intergenerational Mobility Variation over Time and Place. Chapter 2 in Miles Corak (ed.), Generational Income Mobility in North America and Europe. Cambridge, UK: Cambridge University Press, 2004. S

Stiglitz, Joseph. 2012. The Price of Inequality: How Today's Divided Society Endangers Our Future. W. W. Norton Company

Tsang, M. (2000). Education and national development in China since 1949: Oscillating policies and enduring dilemmas. China Review (pp. 579-618).

Wei, Xin, Mun Tsang, Weibin Xu and Liang-Kun Chen. 1999. Education and Earnings in Rural China. Education Economics, Vol. 7, No.2, pp 167-187.

World Development Report (WDR) (2005): Equity and Development, The World bank. Yang, Dennis, 2004. Education and allocative efficiency: household income growth 
during rural reforms in China, Journal of Development Economics, Elsevier, vol. 74(1), pages 137-162, June.

Yang, Dennis Tao and An, Mark Yuying, 2002. "Human capital, entrepreneurship, and farm household earnings, Journal of Development Economics, Elsevier, vol. 68(1), pages 65-88, June.

Zimmerman, David. 1992. Regression toward Mediocrity in Economic Stature. American Economic Review, Vol. 82, Iss. 3, pp. 409-429. 
Tables

Table 1A: Descriptive Statistics on Parents-Children

\begin{tabular}{|c|c|c|c|c|c|c|c|c|}
\hline \multirow{3}{*}{ Sample } & \multirow{2}{*}{\multicolumn{2}{|c|}{ Full sample }} & \multicolumn{6}{|c|}{ Means of Variables for Different Groups } \\
\hline & & & \multicolumn{4}{|c|}{ Primary school as the cut-off } & \multicolumn{2}{|c|}{ Junior middle as the cut-of } \\
\hline & Mean & $\begin{array}{l}\text { Standard } \\
\text { deviation }\end{array}$ & $\begin{array}{c}\text { Farm } \\
\text { low edu }\end{array}$ & $\begin{array}{c}\text { Off-farm } \\
\text { low edu }\end{array}$ & $\begin{array}{c}\text { Farm } \\
\text { high edu }\end{array}$ & $\begin{array}{l}\text { Off-farm } \\
\text { high edu }\end{array}$ & $\begin{array}{c}\text { Farm } \\
\text { high edu }\end{array}$ & $\begin{array}{l}\text { Off-farm } \\
\text { high edu }\end{array}$ \\
\hline \multicolumn{9}{|l|}{ Children in general } \\
\hline Children's age & 25.1 & 7.2 & 28.8 & 25.2 & 23.4 & 22.0 & 23.1 & 21.2 \\
\hline Children's years of schooling & 8.7 & 2.5 & 7.7 & 8.7 & 9.1 & 9.7 & 9.4 & 10.1 \\
\hline Dummy $=1$ if children more than primary schooling & 0.9 & 0.4 & 0.7 & 0.8 & 0.9 & 1.0 & 0.9 & 1.0 \\
\hline \multicolumn{9}{|l|}{$\underline{\text { Daughters }}$} \\
\hline Daughters' age & 24.3 & 7.1 & 28.5 & 24.0 & 22.4 & 21.2 & 22.1 & 20.7 \\
\hline Daughters' years of schooling & 8.6 & 2.6 & 7.4 & 8.5 & 9.0 & 9.6 & 9.2 & 9.9 \\
\hline Dummy $=1$ if daughter more than primary schooling & 0.8 & 0.4 & 0.7 & 0.8 & 0.9 & 0.9 & 0.9 & 1.0 \\
\hline \multicolumn{9}{|l|}{$\underline{\text { Sons }}$} \\
\hline Sons' age & 25.6 & 7.2 & 29.0 & 26.1 & 24.0 & 22.5 & 23.8 & 21.7 \\
\hline Sons' years of schooling & 8.9 & 2.4 & 7.9 & 8.9 & 9.1 & 9.8 & 9.4 & 10.2 \\
\hline Dummy $=1$ if son more than primary schooling & 0.9 & 0.3 & 0.8 & 0.9 & 0.9 & 1.0 & 0.9 & 1.0 \\
\hline \multicolumn{9}{|l|}{ Father } \\
\hline Father's age & 53.2 & 8.4 & 58.4 & 53.9 & 50.8 & 49.0 & 50.1 & 48.0 \\
\hline Father's years of schooling & 6.4 & 3.0 & 3.6 & 4.4 & 8.1 & 8.6 & 9.5 & 9.8 \\
\hline Dummy $=1$ if father more than primary schooling & 0.5 & 0.5 & 0 & 0 & 0.9 & 1.0 & 1.0 & 1.0 \\
\hline Dummy $=1$ if father in off-farming & 0.3 & 0.5 & 0 & 0.9 & 0 & 0.9 & 0.0 & 0.9 \\
\hline \multicolumn{9}{|l|}{ Mother } \\
\hline Mother's age & 51.0 & 8.4 & 55.8 & 51.2 & 48.8 & 47.2 & 48.1 & 46.2 \\
\hline Mother's years of schooling & 4.5 & 3.1 & 2.4 & 3.2 & 5.5 & 6.3 & 6.4 & 7.1 \\
\hline Dummy $=1$ if mother more than primary schooling & 0.3 & 0.4 & 0 & 0 & 0.4 & 0.5 & 0.6 & 0.6 \\
\hline Dummy $=1$ if mother in off-farming & 0.1 & 0.3 & 0 & 0.3 & 0 & 0.3 & 0.0 & 0.3 \\
\hline \multicolumn{9}{|l|}{ Parents in general } \\
\hline Parents' average years of schooling & 5.4 & 2.7 & 3.0 & 3.8 & 6.8 & 7.5 & 8.0 & 8.4 \\
\hline Dummy $=1$ if at least one parent more than primary schooling & 0.6 & 0.5 & 0 & 0 & 1 & 1 & 1.0 & 1.0 \\
\hline Dummy $=1$ if at least one parent in in off-farming & 0.3 & 0.5 & 0 & 1 & 0 & 1 & 0 & 1 \\
\hline
\end{tabular}

Notes. 1) Observations: 7264 for full sample: 2916 for daughters and 4348 for sons; 2) Observations for the four groups in the primary school cutoff: farm and low edu (2494), off-farm and low edu (621), farm and high edu (2403), off-farm and high edu (1746); 3) Observations for the junior middle school cut-off: farm and high edu (636), off-farm and high edu (735); 4) For primary school cutoff, "High edu" stands for more than primary schooling and "low edu" stands for primary schooling or less; 5) For junior middle school cut-off, "High edu" stands for more than junior middle schooling 


\begin{tabular}{|c|c|c|c|c|c|c|}
\hline \multirow{3}{*}{ Sample } & & & \multicolumn{4}{|c|}{ Mean Values of Variables } \\
\hline & \multicolumn{2}{|c|}{ Full sample } & \multicolumn{4}{|c|}{ Primary school cut-off } \\
\hline & Mean & $\begin{array}{c}\text { Standard } \\
\text { deviation }\end{array}$ & $\begin{array}{c}\text { Farm } \\
\text { low edu }\end{array}$ & $\begin{array}{c}\text { Off-farm } \\
\text { low edu }\end{array}$ & $\begin{array}{c}\text { Farm } \\
\text { high edu }\end{array}$ & $\begin{array}{l}\text { Off-farm } \\
\text { high edu }\end{array}$ \\
\hline \multicolumn{7}{|l|}{ Parents } \\
\hline Parents' age & 44.8 & 10.0 & 45.6 & 45.9 & 40.5 & 41.9 \\
\hline Parents' years of schooling & 6.6 & 2.8 & 6.4 & 6.9 & 7.6 & 7.7 \\
\hline Dummy $=1$ if parents more than primary schooling & 0.6 & 0.5 & 0.5 & 0.6 & 0.7 & 0.8 \\
\hline \multicolumn{7}{|l|}{ Grandfathers } \\
\hline Grandfather's age & 74.5 & 12.3 & 75.7 & 76.4 & 68.3 & 70.1 \\
\hline Grandfather's years of schooling & 2.9 & 2.7 & 2.0 & 2.9 & 7.2 & 7.3 \\
\hline Dummy $=1$ if grandfather more than primary schooling & 0.2 & 0.4 & 0 & 0 & 1.0 & 0.9 \\
\hline Dummy = 1 if grandfather in off-farming & 0.1 & 0.3 & 0 & 1.0 & 0 & 1.0 \\
\hline \multicolumn{7}{|l|}{ Grandmothers } \\
\hline Grandmother's age & 71.8 & 11.8 & 72.9 & 73.4 & 66.2 & 68.1 \\
\hline Grandmother's years of schooling & 1.2 & 1.9 & 0.8 & 1.1 & 3.2 & 3.0 \\
\hline Dummy $=1$ if grandmother more than primary schooling & 0.1 & 0.2 & 0 & 0 & 0.5 & 0.3 \\
\hline Dummy $=1$ if grandmother in off-farming & 0.0 & 0.1 & 0 & 0.2 & 0 & 0.2 \\
\hline \multicolumn{7}{|l|}{ Grandparents in general } \\
\hline Grandparents' average years of schooling & 2.2 & 2.1 & 1.5 & 2.1 & 5.5 & 5.5 \\
\hline Dummy $=1$ if at least one grandparent more than primary schooling & 0.2 & 0.4 & 0 & 0 & 1 & 1 \\
\hline Dummy $=1$ if at least one grandparent in in off-farming & 0.1 & 0.3 & 0 & 1 & 0 & 1 \\
\hline
\end{tabular}

Notes

1) Observations: 14777 for full sample;

2) Observations for the groups in the primary school cutoff: farm and low edu (11571), off-farm and low edu (690), farm and high edu (2204), off-farm and high edu (312);

3) For primary school cut-off, "High edu" stands for more than primary schooling and "low edu" stands for primary schooling or less; 
Table 2: Impact of family background on children's years of schooling (primary schooling as the threshold for parental education)

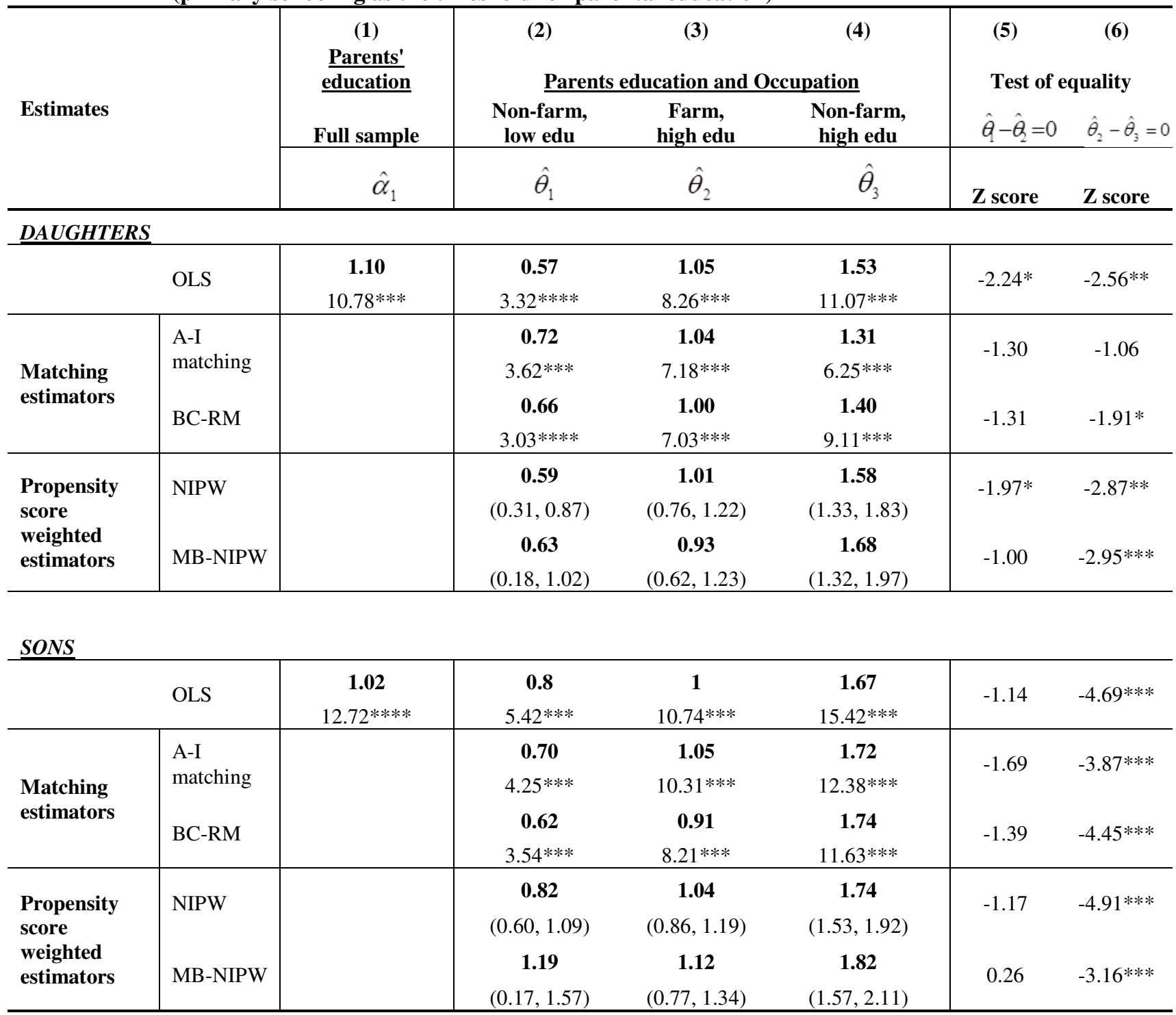

Notes

1) Dependent variable=children's years of schooling;

2) For the column (1), the interest variable=parents' education dummy, dummy $=1$ if at least one of parents more than primary schooling, $0=$ otherwise;

3) For all columns, the control variables are children's age, children's age squared, mother's age, mother's age squared, father's age, father's age squared;

4) For the columns (2) - (4), the interest variable is parents' education and occupation status dummy. The dummy=1 if treatment group, $=0$ otherwise; base group is parents (farm, low edu)

5) A-I matching=Abadie and Imbens (2002)

6) $\mathrm{BC}-\mathrm{RM}=$ Biased corrected radius matching;

7) NIPW = normalized inverse probability weighted propensity score estimator of Hirano and Imbens (2001);

8) MB-NIPW = minimum-biased normalized inversed probability weighted estimator;

9) The computation uses STATA program written by Millimet and Tchernis (2013);

10) For NIPW and MB-NIPW, $90 \%$ confidence interval is given in parentheses, which is boostrapped using 250 replications;

11) "high edu" stands for more than primary schooling, "low edu" stands for primary schooling or less;

$12) * * *, * *$, and $*$ Denotes statistical significance at the $1 \%, 5 \%$, and $10 \%$ level respectively. 
Table 3: Impact of grandparents' family background on parents' years of schooling (primary schooling as the threshold for Grandparents' education)

\begin{tabular}{|c|c|c|c|c|c|c|c|}
\hline \multirow{3}{*}{ Estimates } & & \multirow{2}{*}{$\begin{array}{c}\text { (1) } \\
\text { Grandparents' } \\
\underline{\text { education }} \\
\text { Full sample }\end{array}$} & \multicolumn{3}{|c|}{$\begin{array}{c}\text { (2) } \\
\text { Grandparents education and Occupation } \\
\end{array}$} & \multicolumn{2}{|c|}{$\begin{array}{l}(5) \\
\text { Test of equality }\end{array}$} \\
\hline & & & $\begin{array}{c}\text { Non-farm, } \\
\text { low edu }\end{array}$ & $\begin{array}{c}\text { Farm, } \\
\text { high edu }\end{array}$ & $\begin{array}{c}\text { Non-farm, } \\
\text { high edu }\end{array}$ & $\hat{\theta}-\hat{\theta}_{2}=0$ & $\hat{\theta}_{2}-\hat{\theta}_{3}=0$ \\
\hline & & $\hat{\alpha}_{1}$ & $\hat{\theta}_{1}$ & $\hat{\theta}_{2}$ & $\hat{\theta}_{3}$ & $Z$ score & $\mathbf{Z}$ score \\
\hline \multicolumn{8}{|l|}{ Mothers } \\
\hline & OLS & $\begin{array}{c}\mathbf{1 . 0 3} \\
12.05^{* * *} \\
\end{array}$ & $\begin{array}{c}\mathbf{0 . 5 8} \\
3.66 * * * \\
\end{array}$ & $\begin{array}{c}\mathbf{0 . 9 9} \\
10.48 * * *\end{array}$ & $\begin{array}{r}1.48 \\
6.69 * * * \\
\end{array}$ & $-2.22 *$ & $-2.03 *$ \\
\hline $\begin{array}{l}\text { Matching } \\
\text { estimator }\end{array}$ & $\begin{array}{l}\text { A-I } \\
\text { matching } \\
\text { BC-RM }\end{array}$ & & $\begin{array}{c}\mathbf{0 . 6 7} \\
4.07 * * * \\
\mathbf{0 . 7 8} \\
4.33 * * *\end{array}$ & $\begin{array}{c}\mathbf{0 . 9 8} \\
9.14 * * * \\
\mathbf{1 . 0 1} \\
8.99 * * *\end{array}$ & $\begin{array}{c}\mathbf{1 . 6 3} \\
6.85 * * * \\
\mathbf{1 . 4 7} \\
6.67 * * *\end{array}$ & -1.08 & $-2.48 * *$ \\
\hline $\begin{array}{l}\text { Propensity } \\
\text { score } \\
\text { weighted } \\
\text { estimator }\end{array}$ & $\begin{array}{l}\text { NIPW } \\
\text { MB- } \\
\text { NIPW } \\
\end{array}$ & & $\begin{array}{c}\mathbf{0 . 6 2} \\
(0.39,0.89) \\
\mathbf{0 . 6 6} \\
(0.22,1.08) \\
\end{array}$ & $\begin{array}{c}\mathbf{1 . 0 0} \\
(0.87,1.15) \\
\mathbf{1 . 0 4} \\
(0.82,1.22) \\
\end{array}$ & $\begin{array}{c}\mathbf{1 . 5 1} \\
(1.05,1.88) \\
\mathbf{1 . 2 4} \\
(0.91,1.92) \\
\end{array}$ & $\begin{array}{l}-2.02 * \\
-1.36\end{array}$ & $\begin{array}{c}-2.11 * * \\
-0.46\end{array}$ \\
\hline \multicolumn{8}{|l|}{ Fathers } \\
\hline & OLS & $\begin{array}{c}\mathbf{0 . 7 6} \\
10.64 * * * \\
\end{array}$ & $\begin{array}{c}\mathbf{0 . 4 2} \\
3.31 * * * \\
\end{array}$ & $\begin{array}{c}\mathbf{0 . 7 8} \\
10.04 * * * \\
\end{array}$ & $\begin{array}{c}\mathbf{0 . 8 0} \\
4.15 * * * \\
\end{array}$ & $-2.46^{* *}$ & -0.09 \\
\hline $\begin{array}{l}\text { Matching } \\
\text { estimator }\end{array}$ & $\begin{array}{l}\text { A-I } \\
\text { matching } \\
\text { BC-RM }\end{array}$ & & $\begin{array}{c}\mathbf{0 . 4 4} \\
3.35 * * * \\
\mathbf{0 . 5 5} \\
3.57 * * * \\
\end{array}$ & $\begin{array}{c}\mathbf{0 . 9 1} \\
10.09 * * * \\
\mathbf{0 . 8 9} \\
9.73 * * * \\
\end{array}$ & $\begin{array}{c}\mathbf{0 . 7 7} \\
3.44 * * * \\
\mathbf{0 . 7 3} \\
3.83 * * * \\
\end{array}$ & $-2.94 * * *$ & 0.75 \\
\hline $\begin{array}{l}\text { Propensity } \\
\text { score } \\
\text { weighted } \\
\text { estimator }\end{array}$ & $\begin{array}{l}\text { NIPW } \\
\text { MB- } \\
\text { NIPW }\end{array}$ & & $\begin{array}{c}\mathbf{0 . 4 1} \\
(0.22,0.62) \\
\mathbf{0 . 2 1} \\
(-0.04,0.65) \\
\end{array}$ & $\begin{array}{c}\mathbf{0 . 7 8} \\
(0.66,0.92) \\
\mathbf{0 . 7 6} \\
(0.61,0.95) \\
\end{array}$ & $\begin{array}{c}\mathbf{0 . 8 1} \\
(0.51,1.24) \\
\mathbf{0 . 7 3} \\
(0.42,1.17) \\
\end{array}$ & $-2.41 * *$ & -0.11 \\
\hline
\end{tabular}

Notes

1) Dependent variable=parents' years of schooling;

2) For the column (1), the interest variable=grandparents' education dummy, dummy $=1$ if at least one of grandparents more than primary schooling, $0=$ otherwise;

3) For all columns, the control variables are parents' age, parents' age squared, grandmother's age, grandmother's age squared, grandfather's age, grandfather's age squared;

4) For the columns (2) - (4), the interest variable is grandparents' education and occupation status dummy. The dummy equals 1 if household belongs to 'treatment' group, and 0 otherwise; the base group is parents (farm, low edu)

5) A-I matching=Abadie and Imbens (2002)

6) $\mathrm{BC}-\mathrm{RM}=$ Biased corrected radius matching;

7) NIPW = normalized inverse probability weighted propensity score estimator of Hirano and Imbens (2001);

8) MB-NIPW = minimum-biased normalized inversed probability weighted estimator;

9) The computation uses STATA program written by Millimet and Tchernis (2013);

10) For NIPW and MB-NIPW, $90 \%$ confidence interval is given in parentheses, which is boostrapped using 250 replications;

11) "high edu" stands for more than primary schooling, "low edu" stands for primary schooling or less;

12) $* * *, * *$, and * Denotes statistical significance at $1 \%, 5 \%$, and $10 \%$ level. 
Table 4: Impact of parents' family background on childrens' years of schooling (junior middle school as the threshold for parents' education)

\begin{tabular}{|c|c|c|c|c|c|c|c|}
\hline \multirow{3}{*}{\multicolumn{2}{|c|}{ Estimates }} & \multirow{2}{*}{$\begin{array}{c}\text { (1) } \\
\frac{\text { Parents' }}{\text { education }} \\
\text { Full sample }\end{array}$} & \multicolumn{3}{|c|}{$\begin{array}{l}\text { (2) } \\
\text { Parents' education and Occupation } \\
\end{array}$} & \multicolumn{2}{|c|}{$\begin{array}{l}\text { (5) } \\
\text { Test of equality }\end{array}$} \\
\hline & & & $\begin{array}{c}\text { Non-farm, } \\
\text { low edu }\end{array}$ & $\begin{array}{c}\text { Farm, } \\
\text { high edu }\end{array}$ & $\begin{array}{c}\text { Non-farm, } \\
\text { high edu }\end{array}$ & $\hat{\theta}-\hat{\theta}_{2}=0$ & $\hat{\theta}_{2}-\hat{\theta}_{3}=0$ \\
\hline & & $\hat{\alpha}_{1}$ & $\hat{\theta}_{1}$ & $\hat{\theta}_{2}$ & $\hat{\theta}_{3}$ & z score & z score \\
\hline \multicolumn{8}{|c|}{ DAUGHTERS } \\
\hline & OLS & $\begin{array}{c}\mathbf{1 . 3 6} \\
9.74 * * * \\
\end{array}$ & $\begin{array}{c}\mathbf{0 . 5 7} \\
3.32 * * * \\
\end{array}$ & $\begin{array}{c}1.19 \\
6.21 * * * \\
\end{array}$ & $\begin{array}{c}\mathbf{1 . 7 8} \\
9.99 * * * \\
\end{array}$ & $-2.41 * *$ & $-2.25 * *$ \\
\hline $\begin{array}{l}\text { Matching } \\
\text { estimator }\end{array}$ & $\begin{array}{l}\text { A-I } \\
\text { matching } \\
\text { BC-RM }\end{array}$ & & $\begin{array}{c}\mathbf{0 . 7 2} \\
3.62 * * * \\
\mathbf{0 . 6 6} \\
3.03 * * *\end{array}$ & $\begin{array}{c}1.69 \\
6.42 * * * \\
1.22 \\
5.37 * * *\end{array}$ & $\begin{array}{c}\mathbf{2 . 1 7} \\
6.94 * * * \\
\mathbf{1 . 9 3} \\
10.74 * * *\end{array}$ & $-2.94 * * *$ & $-2.45^{* *}$ \\
\hline $\begin{array}{l}\text { Propensity } \\
\text { score } \\
\text { weighted } \\
\text { estimator }\end{array}$ & $\begin{array}{l}\text { NIPW } \\
\text { MB- } \\
\text { NIPW }\end{array}$ & & $\begin{array}{c}\mathbf{0 . 5 9} \\
(0.31,0.87) \\
\mathbf{0 . 6 3} \\
(0.18,1.02) \\
\end{array}$ & $\begin{array}{c}\mathbf{1 . 2 6} \\
(0.96,1.61) \\
\mathbf{1 . 2 4} \\
(0.75,1.49) \\
\end{array}$ & $\begin{array}{c}\mathbf{1 . 8 5} \\
(1.53,2.14) \\
\mathbf{1 . 8 7} \\
(1.47,2.24) \\
\end{array}$ & $-2.46 * *$ & $\begin{array}{l}-2.13 * * \\
-1.92 *\end{array}$ \\
\hline \multicolumn{8}{|l|}{$\underline{\text { SONS }}$} \\
\hline & OLS & $\begin{array}{c}\mathbf{1 . 4 2} \\
12.21 * * * \\
\end{array}$ & $\begin{array}{c}\mathbf{0 . 8 1} \\
5.42 * * * \\
\end{array}$ & $\begin{array}{c}\mathbf{1 . 3 1} \\
8.31 * * * \\
\end{array}$ & $\begin{array}{c}\mathbf{2 . 0 8} \\
14.37 * * * \\
\end{array}$ & $-2.36 * *$ & $-3.59 * * *$ \\
\hline $\begin{array}{l}\text { Matching } \\
\text { estimator }\end{array}$ & $\begin{array}{l}\text { A-I } \\
\text { matching } \\
\text { BC-RM }\end{array}$ & & $\begin{array}{c}\mathbf{0 . 7 0} \\
4.25 * * * \\
\mathbf{0 . 6 2} \\
3.54 * * * \\
\end{array}$ & $\begin{array}{c}1.29 \\
6.33 * * * \\
1.41 \\
8.22 * * *\end{array}$ & $\begin{array}{c}\mathbf{2 . 0 7} \\
8.26 * * * \\
\mathbf{2 . 5 4} \\
14.76 * * * \\
\end{array}$ & $-3.22 * * *$ & $-4.65 * * *$ \\
\hline $\begin{array}{l}\text { Propensity } \\
\text { score } \\
\text { weighted } \\
\text { estimator }\end{array}$ & $\begin{array}{l}\text { NIPW } \\
\text { MB- } \\
\text { NIPW }\end{array}$ & & $\begin{array}{c}\mathbf{0 . 8 2} \\
(0.60,1.09) \\
\mathbf{1 . 1 9} \\
(0.62,1.57) \\
\end{array}$ & $\begin{array}{c}\mathbf{1 . 4 1} \\
(1.16,1.66) \\
\mathbf{1 . 6 1} \\
(1.26,1.94) \\
\end{array}$ & $\begin{array}{c}\mathbf{2 . 2 1} \\
(1.92,2.44) \\
\mathbf{2 . 2 3} \\
(1.91,2.54) \\
\end{array}$ & $-2.64 * *$ & $-3.87 * * *$ \\
\hline
\end{tabular}

Notes

1) Dependent variable=children's years of schooling;

2) For the column (1), the interest variable=parents' education dummy, dummy $=1$ if at least one of parents more than junior middle school, $0=$ otherwise

3) For all columns, the control variables are children's age, children's age squared, mother's age, mother's age squared, father's age, father's age squared;

4) For the columns (2) - (4), the interest variable is parents' education and occupation status dummy. The dummy=1 if treatment group, $=0$ otherwise; base group is parents (farm, low edu)

5) A-I matching=Abadie and Imbens (2002)

6) $\mathrm{BC}-\mathrm{RM}=$ Biased corrected radius

matching;

7) NIPW = normalized inverse probability weighted propensity score estimator of Hirano and Imbens (2001);

8) MB-NIPW = minimum-biased normalized inversed probability weighted estimator;

9) The computation uses STATA program written by Millimet and Tchernis (2013);

10) For NIPW and MB-NIPW, $90 \%$ confidence interval is given in parentheses, which is boostrapped using 250 replications;

11) "high edu" stands for more than junior middle schooling, "low edu" stands for junior middle schooling or less;

12) $* * *, * *$, and $*$ Denotes statistical significance at $1 \%, 5 \%$, and $10 \%$ level. 
Table 5: Income and education expenditure for the six types of households

\begin{tabular}{l|c|c|c|c|c|c}
\hline \multirow{2}{*}{} & \multicolumn{3}{c|}{ Primary school as cut-off } & \multicolumn{2}{c}{$\begin{array}{c}\text { Middle school } \\
\text { cut-off }\end{array}$} \\
\cline { 2 - 7 } & $\begin{array}{c}\text { Farm } \\
\text { low } \\
\text { edu }\end{array}$ & $\begin{array}{c}\text { Off- } \\
\text { farm } \\
\text { low } \\
\text { edu }\end{array}$ & $\begin{array}{c}\text { Farm } \\
\text { high } \\
\text { edu }\end{array}$ & $\begin{array}{c}\text { Off- } \\
\text { farm } \\
\text { high } \\
\text { edu }\end{array}$ & $\begin{array}{c}\text { Farm } \\
\text { high } \\
\text { edu }\end{array}$ & $\begin{array}{c}\text { Off-farm } \\
\text { high edu }\end{array}$ \\
\hline Panel 5A: Household per capita income (yuan) \\
\hline income in 2002 & 2189 & 3159 & 2449 & 3445 & 2551 & 3692 \\
3-year average income (2000-2002) & 2111 & 2947 & 2318 & 3170 & 2411 & 3369 \\
5-year average income (1998-2002) & 1972 & 2730 & 2155 & 2918 & 2236 & 3102 \\
\hline \multicolumn{7}{|l|}{} \\
\hline Panel 5B: household education expenditure per school-age child (yuan) \\
\hline Daughters & 443 & 813 & 879 & 986 & 1165 & 1097 \\
Sons & 528 & 758 & 779 & 1338 & 868 & 1498 \\
Average & 489 & 782 & 822 & 1183 & 992 & 1324 \\
\hline
\end{tabular}

Note: school-age children aged 6 to 18 years 
Table 6: Test of complementarity between parents' education and occupation in children's years of schooling

\begin{tabular}{|c|c|c|c|c|c|}
\hline & & $\begin{array}{c}\text { (1) } \\
\underline{\text { Standard }} \\
\text { specification }\end{array}$ & $\begin{array}{c}(2) \\
\text { Margin } \\
\text { parents' } \\
\text { in farm } \\
\text { farm } h \\
\end{array}$ & $\begin{array}{c}\text { (3) } \\
\text { effect of } \\
\frac{\text { ducation }}{\text { nd non- }} \\
\text { seholds } \\
\end{array}$ & $\begin{array}{c}\text { (4) } \\
\text { Test of equality } \\
\underline{\text { between }} \\
\text { column (2) and (3) }\end{array}$ \\
\hline & & $\hat{\beta}_{3}$ & Farm & $\begin{array}{l}\text { Non- } \\
\text { farm }\end{array}$ & Z-score \\
\hline \multicolumn{6}{|l|}{$\begin{array}{l}\text { Panel 6A: children- } \\
\text { parents }\end{array}$} \\
\hline \multicolumn{6}{|l|}{ Daughters } \\
\hline & OLS & $\begin{array}{r}-\mathbf{- 0 . 0 4} \\
-0.23 \\
\end{array}$ & $\begin{array}{c}\mathbf{1 . 0 5} \\
8.26 * * * \\
\end{array}$ & $\begin{array}{c}\mathbf{0 . 8 8} \\
5.02 * * * \\
\end{array}$ & 0.77 \\
\hline Matching estimator & $\begin{array}{l}\text { A-I } \\
\text { matching } \\
\text { BC-RM }\end{array}$ & & $\begin{array}{c}\mathbf{1 . 0 5} \\
7.18 \\
\mathbf{1 . 0 0} \\
7.03 * * *\end{array}$ & $\begin{array}{c}\mathbf{0 . 8 3} \\
4.27 \\
\mathbf{0 . 9 6} \\
4.93^{* * *}\end{array}$ & 0.16 \\
\hline \multirow{2}{*}{$\begin{array}{l}\text { Propensity score } \\
\text { weighted estimator }\end{array}$} & NIPW & & $\begin{array}{c}\mathbf{1 . 0 1} \\
(0.76 \\
1.22)\end{array}$ & $\begin{array}{c}\mathbf{0 . 8 8} \\
(0.55 \\
1.14)\end{array}$ & 0.27 \\
\hline & $\begin{array}{l}\text { MB- } \\
\text { NIPW }\end{array}$ & & $\begin{array}{r}\mathbf{0 . 9 3} \\
(0.62 \\
1.23)\end{array}$ & $\begin{array}{c}\mathbf{1 . 0 1} \\
(0.44 \\
1.57)\end{array}$ & -0.15 \\
\hline \multicolumn{6}{|l|}{ Sons } \\
\hline & OLS & $\begin{array}{r}-\mathbf{0 . 1 5} \\
-0.86 \\
\end{array}$ & $\begin{array}{c}\mathbf{1} \\
10.74^{* * * *}\end{array}$ & $\begin{array}{c}\mathbf{0 . 7} \\
4.64 * * * \\
\end{array}$ & $1.71^{*}$ \\
\hline Matching estimator & $\begin{array}{l}\text { A-I } \\
\text { matching } \\
\text { BC-RM }\end{array}$ & & $\begin{array}{c}\mathbf{1 . 0 5} \\
10.31 \\
\mathbf{0 . 9 1} \\
8.21 * * * \\
\end{array}$ & $\begin{array}{c}\mathbf{0 . 6 6} \\
3.81 \\
\mathbf{0 . 8 6} \\
5.52 * * * \\
\end{array}$ & $\begin{array}{c}1.94 * * \\
0.26\end{array}$ \\
\hline \multirow{2}{*}{$\begin{array}{l}\text { Propensity score } \\
\text { weighted estimator }\end{array}$} & NIPW & & $\begin{array}{c}\mathbf{1 . 0 4} \\
(0.86 \\
1.19)\end{array}$ & $\begin{array}{c}\mathbf{0 . 6 3} \\
(0.34 \\
0.91)\end{array}$ & $2.12 * *$ \\
\hline & $\begin{array}{l}\text { MB- } \\
\text { NIPW }\end{array}$ & & $\begin{array}{c}\mathbf{1 . 1 2} \\
(0.77, \\
1.34) \\
\end{array}$ & $\begin{array}{r}\mathbf{0 . 5 9} \\
(0.05 \\
1.04) \\
\end{array}$ & $1.74^{*}$ \\
\hline
\end{tabular}

Notes

1) For the column (1), the dependent variable is years of schooling of children generation, the regression includes the family background occupation dummy, family education dummy, the interaction of the two dummies, and the controls; but the table only reports the coefficient of the interaction of two dummies;

2) For the column (1), family background occupation dummy $=1$ if off-farm, $=0$ otherwise, family background education dummy $=1$ if more than primary schooling, $0=$ otherwise;

3) For all columns, the control variables are children's age, children's age squared, mother's age, mother's age squared, father's age, father's age squared;

4) Column (2) and (3) break the full sample into two subsamples based on family occupation background, for each subsample, the treatment is family education background high, which is more than primary schooling;

5) A-I matching=Abadie and Imbens (2002)

6) $\mathrm{BC}-\mathrm{RM}=$ Biased corrected radius matching;

7) NIPW = normalized inverse probability weighted propensity score estimator of Hirano and Imbens (2001);

8) MB-NIPW = minimum-biased normalized inversed probability weighted estimator;

9) The computation uses STATA program written by Millimet and Tchernis (2013);

10) For NIPW and MB-NIPW, $90 \%$ confidence interval is given in parentheses, which is boostrapped using 250 replications;

$11) * * *, * *$, and $*$ Denotes statistical significance at $1 \%, 5 \%$, and $10 \%$ level; 
Panel 6B: parents-grandparents

\begin{tabular}{|c|c|c|c|c|c|}
\hline & $\begin{array}{c}\text { (1) } \\
\text { Standard } \\
\text { specification }\end{array}$ & \multicolumn{2}{|c|}{$\begin{array}{c}\text { (2) } \\
\text { Marginal effect of parents' } \\
\frac{\text { education in farm and non- }}{\text { farm households }}\end{array}$} & \multirow{2}{*}{$\begin{array}{c}\text { (4) } \\
\frac{\text { Test of equality }}{\underline{\text { between }}} \\
\text { column (2) and (3) } \\
\text { Z-score }\end{array}$} \\
\hline & & $\hat{\beta}_{3}$ & Farm & Non-farm & \\
\hline \multicolumn{6}{|l|}{ Mothers } \\
\hline \multicolumn{2}{|r|}{ OLS } & $\begin{array}{l}\mathbf{- 0 . 0 9} \\
-0.36\end{array}$ & $\begin{array}{c}\mathbf{0 . 9 9} \\
10.48^{* * *}\end{array}$ & $\begin{array}{c}\mathbf{1 . 0 4} \\
4.07 * * *\end{array}$ & -0.18 \\
\hline $\begin{array}{l}\text { Matching } \\
\text { estimators }\end{array}$ & $\begin{array}{l}\text { A-I } \\
\text { matching } \\
\text { BC-RM }\end{array}$ & & $\begin{array}{c}\mathbf{0 . 9 8} \\
9.14 \\
\mathbf{1 . 0 1} \\
8.99 * * * \\
\end{array}$ & $\begin{array}{c}\mathbf{0 . 9 6} \\
3.64 \\
\mathbf{1 . 2 5} \\
4.09 * * * \\
\end{array}$ & -0.73 \\
\hline $\begin{array}{l}\text { Propensity } \\
\text { score } \\
\text { weighted } \\
\text { estimators }\end{array}$ & $\begin{array}{l}\text { NIPW } \\
\text { MB- } \\
\text { NIPW }\end{array}$ & & $\begin{array}{c}\mathbf{1 . 0 0} \\
(0.87,1.15) \\
\mathbf{1 . 0 4} \\
(0.82,1.22) \\
\end{array}$ & $\begin{array}{c}\mathbf{1 . 0 7} \\
(0.51,1.55) \\
\mathbf{1 . 1 0} \\
(0.18,1.94) \\
\end{array}$ & -0.11 \\
\hline \multicolumn{6}{|l|}{ Fathers } \\
\hline & OLS & $\begin{array}{c}\mathbf{- 0 . 3 9} \\
(-1.75)^{*} \\
\end{array}$ & $\begin{array}{c}\mathbf{0 . 7 8} \\
10.04 * * * \\
\end{array}$ & $\begin{array}{c}\mathbf{0 . 4} \\
1.77 * \\
\end{array}$ & 1.56 \\
\hline $\begin{array}{l}\text { Matching } \\
\text { estimators }\end{array}$ & $\begin{array}{l}\text { A-I } \\
\text { matching } \\
\text { BC-RM }\end{array}$ & & $\begin{array}{c}\mathbf{0 . 9} \\
10.09 \\
\mathbf{0 . 8 9} \\
9.73^{* * *}\end{array}$ & $\begin{array}{l}\mathbf{0 . 4 6} \\
1.91 \\
\mathbf{0 . 2 4} \\
0.91 \\
\end{array}$ & $2.36^{* *}$ \\
\hline $\begin{array}{l}\text { Propensity } \\
\text { score } \\
\text { weighted } \\
\text { estimators }\end{array}$ & $\begin{array}{l}\text { NIPW } \\
\text { MB- } \\
\text { NIPW }\end{array}$ & & $\begin{array}{c}\mathbf{0 . 7 8} \\
(0.66,0.92) \\
\mathbf{0 . 7 6} \\
(0.61,0.95) \\
\end{array}$ & $\begin{array}{c}\mathbf{0 . 4 4} \\
(0.05,0.08) \\
\mathbf{0 . 3 7} \\
(-0.28,1.06)\end{array}$ & 0.91 \\
\hline
\end{tabular}


Figure 1: Economic Status based on parents' education and occupation

\begin{tabular}{|c|c|c|}
\hline & Parents' low education & Parents' high education \\
\hline \multirow{2}{*}{ Farmer Parents } & $\mathbf{2 4 9 4}$ & $\mathbf{2 4 0 3}$ \\
& $\begin{array}{c}\text { (children-parents sample) } \\
\mathbf{1 1 , 5 7 1}\end{array}$ & $\begin{array}{c}\text { (children-parents sample) } \\
\text { (parents-grandparents sample) }\end{array}$ \\
\hline $\begin{array}{c}\text { Parents in off- } \\
\text { farm }\end{array}$ & $\begin{array}{c}\text { (p21 } \\
\text { (children-parents sample) }\end{array}$ & $\begin{array}{c}\mathbf{1 7 4 6} \\
\text { (children-parents sample) }\end{array}$ \\
& $\mathbf{6 9 0}$ & $\mathbf{3 1 2}$ \\
\hline
\end{tabular}

